\title{
Inhibitors of the Fibroblast Growth Factor Receptor
}

\author{
Kurt G. Pike
}

\begin{abstract}
Signaling through the fibroblast growth factor receptor (FGFR) tyrosine kinase is crucial to a number of key pharmacological processes; however, dysregulation of this signaling is observed with a number of different cancers suggesting that inhibition of FGFR may provide an important therapeutic agent in the treatment of cancers. This chapter provides an overview of the development of FGFR inhibitors beginning with the identification of nonselective FGFR inhibitors, then describing the medicinal chemistry optimization resulting in the delivery of a number of highly selective FGFR inhibitors, some of which are currently being assessed in clinical trials. The development of isoform selective FGFR inhibitors as well as covalent inhibitors and inhibitors of the inactive form of FGFR are also described.
\end{abstract}

Keywords Fibroblast growth factor receptor, Receptor tyrosine kinase, Selective kinase inhibitor

\section{Contents}

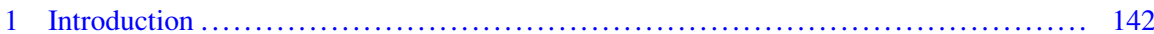

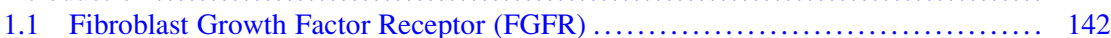

1.2 The Role of FGFR in Cancer ...................................... 143

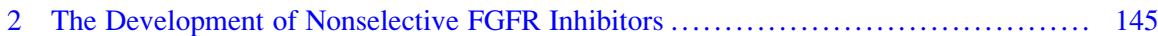

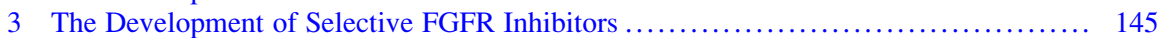

3.1 Pyrido[2,3-d]pyrimidine-Based Inhibitors of FGFR $\ldots \ldots \ldots \ldots \ldots \ldots \ldots \ldots \ldots \ldots 145$

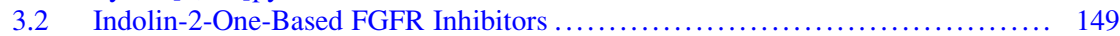

3.3 Benzimidazol-2-Ylhydroquinolin-2-One-Based FGFR Inhibitors ............ 154

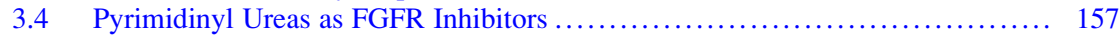

3.5 Pyrazolylaminopyrimidines and Pyrazolylbenzamides as FGFR Inhibitors ...... 160

\footnotetext{
K.G. Pike $(\bowtie)$

Oncology Innovative Medicines, AstraZeneca, Darwin Building, 310 Cambridge Science Park, Milton Road, Cambridge CB4 0WG, UK

e-mail: kurt.pike@astrazeneca.com
} 


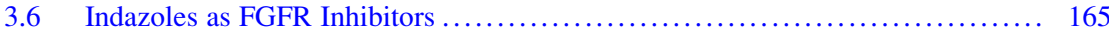

3.7 Imidazopyridine-Based Inhibitors of FGFR ........................... 166

3.8 Quinoxaline- and Naphthyridine-Based Inhibitors of FGFR ................... 167

3.9 Aminopyrazolyl Inhibitors of FGFR ....................................... 169

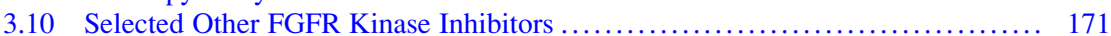

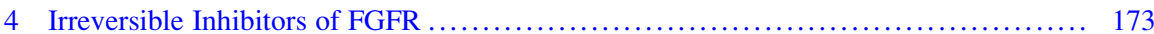

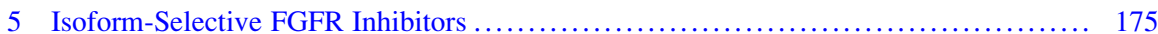

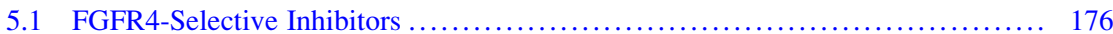

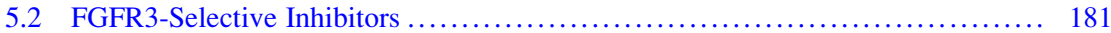

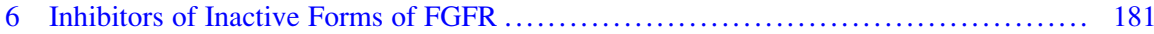

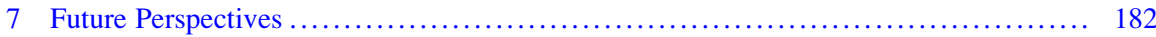

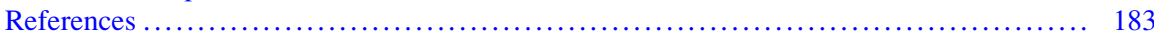

\section{Introduction}

The development of human cancers, in which normal cells are transformed into highly malignant cells, is usually a multistage process that may extend over decades [1]. The transformation process involves cells accumulating a number of genetic changes which result in a specific set of properties commonly referred to as the hallmarks of cancer (including sustained proliferative signaling, evasion of growth suppressors, active invasion and metastasis, replicative immortality, induction of angiogenesis, and resistance to cell death) [2,3]. The genetic alterations acquired by the cell can result in overactivation of growth-promoting oncogenes or the inactivation of growth-inhibitory suppressor genes. Receptor tyrosine kinases, such as epidermal growth factor receptor (EGFR, "Inhibitors of Vascular Endothelial Growth Factor Receptor"), fibroblast growth factor receptor (FGFR), platelet-derived growth factor receptor (PDGFR), and vascular endothelial growth factor receptor (VEGFR, "Inhibitors of Vascular Endothelial Growth Factor Receptor"), represent an important family of genes which have been found to be altered in human cancer.

\subsection{Fibroblast Growth Factor Receptor (FGFR)}

FGFR is a receptor tyrosine kinase (RTK), which consists of an extracellular ligandbinding domain, a single transmembrane helix and an intracellular tyrosine kinase domain. The binding of fibroblast growth factors (FGFs) to FGFR induces receptor dimerization, which in turn results in a conformational shift in the structure of the receptor and activation of the tyrosine kinase domain. Subsequent downstream signaling occurs mostly through FGFR substrate 2 (FRS2) and phospholipase C $\gamma$ (PLC $\gamma$ ), leading to upregulation of the Ras-dependent mitogen-activated protein kinase (MAPK) and Ras-independent phosphoinositide 3-kinase (PI3K)-Akt-signaling pathways. These signals are critical to a number of physiological processes, such as the regulation of organ development, skeletal development, cell proliferation, cell migration, and angiogenesis. There are 18 known FGF ligands, the hormone-like FGFs (FGF19, 21, and 23) and the canonical FGFs (FGF1-10, 16-18, and 20), and 
Fig. 1 Schematic of FGF/FGFR binding

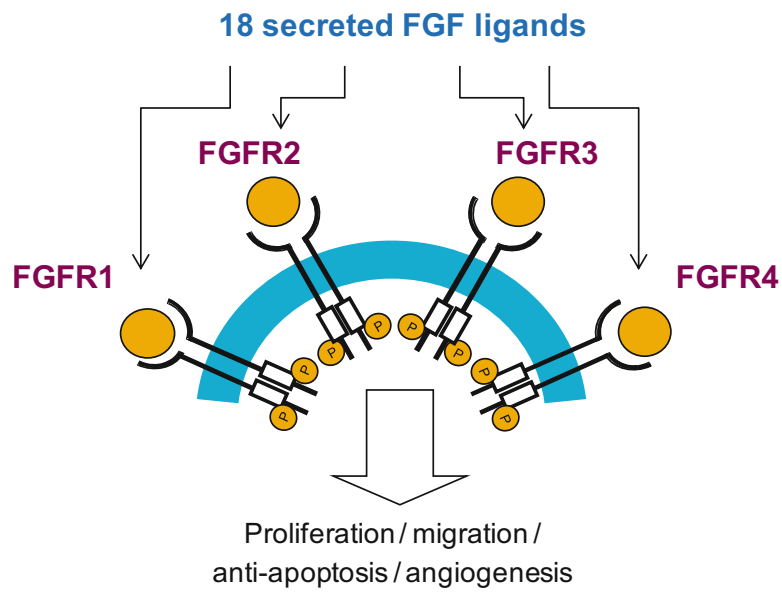

five isoforms of the FGFR receptor, of which only FGFR1-4 possess the intracellular tyrosine kinase domain (Fig. 1). The specificity of the FGF/FGFR interaction is dependent on the ligand-binding capacities of the four receptor isoforms as well as the tissue-specific expression of both ligands and receptors [4-6].

\subsection{The Role of FGFR in Cancer}

FGFRs are known to be overexpressed in many types of human cancer cells, and our understanding of the mechanisms by which FGFR signaling is dysregulated and drives cancer has increased significantly in recent years. FGFRs are among the most commonly mutated kinase genes observed in human cancers. Mutations in FGFR that confer constitutive activation have been seen in many cancers including non-muscle invasive and high-grade bladder cancer (FGFR3 activation), endometrial cancer (FGFR2 activation), and rhabdomyosarcoma (FGFR4 activation). Amplification of FGFR genes will often result in FGFR overexpression, which can also allow ligand-independent signaling to occur. FGFR amplification has been observed in cancers including estrogen receptor-positive breast cancer (FGFR1 amplification), squamous non-small cell lung cancer (FGFR1 amplification), and gastric cancer (FGFR2 amplification). FGFR translocations have been identified in hematologic malignancies, which result in a protein fusing to the intracellular tyrosine kinase domain of an FGFR. This fusion results in the permanent dimerization, and therefore activation, of the protein as well as the removal of mechanisms of feedback inhibition. Such translocations have been observed to result in FGFR3 overexpression and continuous signaling. In addition to aberrations within the receptor proteins, overexpression of the FGF ligands has also been shown to play a role in cancer development; FGF5 overexpression has been observed in a number of lung, esophagus, melanoma, and colon and prostate tumor cell lines, and overexpression/upregulation of FGF2, 8, 17, 18, and 19 has been observed in hepatocellular carcinomas (HCC). 
<smiles>Cc1cc2cc(F)c(Oc3ncnn4cc(OC[C@H](C)OC(=O)[C@H](C)N)c(C)c34)cc2[nH]1</smiles>

Brivanib alaninate<smiles>COC(=O)c1ccc2c(c1)NC(=O)/C2=C(/Nc1ccc(N(C)C(=O)CN2CCN(C)CC2)cc1)c1ccccc1</smiles><smiles>Cc1ccc(C(=O)Nc2ccc(CN3CCN(C)CC3)c(C(F)(F)F)c2)cc1C#Cc1cnc2cccnn12</smiles>

Ponatinib

\begin{tabular}{|c|c|c|c|}
\hline Drug Name & Company & Kinase target & $\begin{array}{c}\text { Clinical development } \\
\text { (indication) }\end{array}$ \\
\hline Brivanib & $\begin{array}{c}\text { Bristol-Myers } \\
\text { Squibb }\end{array}$ & VEGFR, FGFR & $\begin{array}{c}\text { Phase III (CRC, HCC, } \\
\text { liver) }\end{array}$ \\
\hline Nintedanib & Boehringer & VEGFR, PDGFR, & Phase III (NSCLC, \\
Ingelheim & FGFR & ovarian) \\
\hline Lucitanib & Eisai & VEGFR, FGFR1, & Phase I (solid tumors) \\
\hline Ponatinib & Ariad & PDGFR, VEGFR, & Phase II (AML, CML) \\
& Pharmaceutical & FGFR, BCR-ABL & \\
\hline
\end{tabular}

Fig. 2 Structures and targets of selected first generation FGFR inhibitors 


\section{The Development of Nonselective FGFR Inhibitors}

The strong association of dysregulated FGF/FGFR signaling with human cancer has instigated considerable research efforts aimed at the identification of inhibitors of the tyrosine kinase domain of FGFR. The FGFR inhibitors developed to date can be classified in two distinct groups, a first generation of multi-targeted RTK inhibitors and a second generation of FGFR-selective inhibitors. The first generation inhibitors include compounds such as brivanib (BMS-540215), nintedanib (BIBF1120), lucitanib (E-3810), and ponatinib (AP24534) (Fig. 2). While these compounds are inhibitors of FGFR, they also show potent inhibition of a range of other kinases, most notably VEGFR ("Inhibitors of Vascular Endothelial Growth Factor Receptor") and PDGFR [4, 6]. Overall, emerging data from the clinical studies suggest that these nonselective FGFR inhibitors may indeed have utility in the treatment of cancer patients, and despite their polypharmacology, some studies have reported bioactivity against FGFR at the doses employed. However, the main toxicology profile of these agents remains related to pharmacology of VEGFR inhibition [5]. These observations highlight the potential benefit in developing selective FGFR inhibitors with improved therapeutic margins thus enabling more complete target engagement in vivo, in addition to displaying differentiated toxicity profiles.

\section{The Development of Selective FGFR Inhibitors}

\subsection{Pyrido[2,3-d]pyrimidine-Based Inhibitors of FGFR}

The identification of compounds designed to specifically target FGFR was first reported by Connolly et al. from the laboratories of Parke-Davis [7]. The authors utilized high-throughput screening techniques to identify inhibitors of PDGFR and FGFR. This approach resulted in the identification of the pyrido[2,3-d]pyrimidine hit 1 , which showed potent inhibition of FGFR $\left(\mathrm{IC}_{50}=0.13 \mu \mathrm{M}\right)$ in a biochemical assay and was observed to act in an ATP-competitive manner suggesting the compound binds at the ATP-binding site. Additional screening showed hit $\mathbf{1}$ to have broad kinase activity (PDGFR $\mathrm{IC}_{50}=1.11 \mu \mathrm{M}$, EGFR $\mathrm{IC}_{50}=0.45 \mu \mathrm{M}$, and c-Src $\mathrm{IC}_{50}=0.22 \mu \mathrm{M}$ ) leading the authors to speculate that this scaffold might provide a useful start point for the optimization of a variety of novel, targeted kinase inhibitors. The physicochemical properties of hit $\mathbf{1}$, however, resulted in poor exposure following both oral and intraperitoneal (i.p.) dosing; the very poor aqueous solubility, coupled with the inability to form soluble salts with strong acids, precluded intravenous (i.v.) administration. Thus, hit $\mathbf{1}$ was deemed not suitable for in vivo characterization. The efforts to identify potent, selective, and orally available kinase inhibitors were described by Hamby et al. and are summarized below [8] (Fig. 3). 
Fig. 3 Structure of hit 1

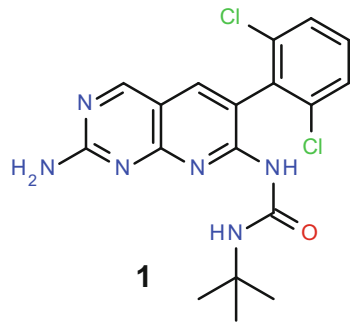

To understand the underlying structure-activity relationship (SAR), the authors began a systematic examination of different positions on the pyrido[2,3-d] pyrimidine scaffold, with particular attention focused on the 6-, 7-, and 2-positions. In the 6-position it was found that phenyl rings possessing small ortho-substituents displayed increased kinase activity against a range of tyrosine kinases (comparing hit $\mathbf{1}$ with compound 2). A crystal structure of hit $\mathbf{1}$ shows the C6-aryl ring adopts an orthogonal relationship to the pyrido[2,3-d]pyrimidine core, presumably driven by the presence of the ortho-chlorine atoms. Further optimization of the phenyl substituent revealed that meta-, but not para-substitution, could infer high levels of selectivity for FGFR over the other tyrosine kinases tested. In particular, the 3,5-dimethoxyphenyl containing compound $\mathbf{3}$ was identified as a potent inhibitor of FGFR with excellent selectivity over closely related kinases (Fig. 4).

Compounds such as $\mathbf{4}$ and $\mathbf{5}$ highlight the opportunity to modulate the kinase inhibitory activity, while simultaneously improving the aqueous solubility of the molecules, through the incorporation of aminoalkyl groups in the 2-position of the pyridopyrimidine ring. Furthermore, compounds $\mathbf{4}$ and $\mathbf{5}$ display significantly improved oral bioavailability, presumably driven by the increased aqueous solubility. Examination of the 7-position revealed the importance of the urea $\mathrm{NH}$ for kinase inhibitory activity and identified a range of tolerated urea substituents, such as compound $\mathbf{6}$; however, large substituents were generally associated with a loss in potency. A combination of the systematically optimized substituents resulted in the discovery of PD173074 (7), a potent and selective inhibitor of FGFR (Fig. 5).

PD173074 (7) was shown to inhibit the autophosphorylation of FGFR1 in NIH 3T3 cells with an $\mathrm{IC}_{50}$ of $0.001-0.005 \mu \mathrm{M}$, whereas the autophosphorylation of VEGFR2 in the same cell line was inhibited with significantly reduced potency $\left(\mathrm{IC}_{50}=0.1-0.2 \mu \mathrm{M}\right)$. PD173074 (7) inhibited the bFGF-stimulated HUVEC growth $\left(\mathrm{IC}_{50}=0.007 \mu \mathrm{M}\right)$ but was less active against VEGF-stimulated HUVEC growth $\left(\mathrm{IC}_{50}=0.194 \mu \mathrm{M}\right)$. The bioavailable nature of 7 allowed for the in vivo characterization of the compound, and it was shown to inhibit bFGF-induced angiogenesis in an in vivo mouse cornea model but was significantly less effective at blocking VEGF-induced angiogenesis in the same model [9].

Researchers at the Kaplan Comprehensive Cancer Center and Skirball Institute of Biomolecular Medicine, in collaboration with researchers at Parke-Davis, successfully crystallized 7 bound into the ATP-binding site of FGFR1 and utilized the X-ray crystal structure to rationalize the observed SAR (Fig. 6) [10]. The pyrido 

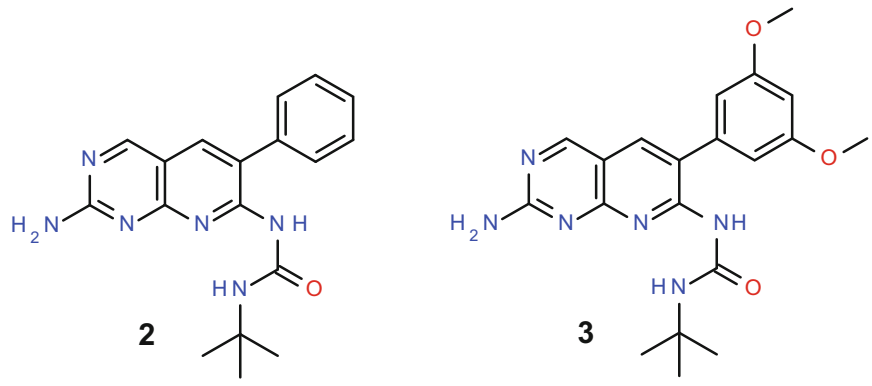

\begin{tabular}{|c|c|c|c|}
\hline Compound & $\mathbf{1}$ & $\mathbf{2}$ & $\mathbf{3}$ \\
\hline FGFR IC $_{50}(\mu \mathrm{M})$ & 0.13 & 3.71 & 0.06 \\
\hline PDGFR IC $_{50}(\mu \mathrm{M})$ & 1.11 & 4.67 & $>50$ \\
\hline EGFR IC $_{50}(\mu \mathrm{M})$ & 0.45 & 5.53 & $>50$ \\
\hline c-Src IC $_{50}(\mu \mathrm{M})$ & 0.22 & $>50$ & $>50$ \\
\hline
\end{tabular}

Fig. 4 SAR of C6-phenyl substitution

[2,3-d]pyrimidine core was found to occupy the same position as the adenosine ring of ATP and forms two hydrogen-bonding interactions with the hinge region of the kinase: between the pyrimidine N3 and the amide nitrogen of Ala564 and between the NH of the 2-amino substituent and the carbonyl oxygen of Ala564. The C6-phenyl ring accesses a hydrophobic back pocket in the binding site with one of the meta-methoxy substituents forming a hydrogen bond to the amide nitrogen of Asp641 at the beginning of the activation loop. The C6-phenyl ring is perpendicular to the plane of the pyrido[2,3-d]pyrimidine core and displays exceptional complimentarily to the shape of the pocket. Interestingly, the back pocket in FGFR1 is lined by two valine residues (Val559 and Val561), whereas, in many kinases this pocket is lined by larger residues. The authors speculate that the highly optimized 3,5-dimethoxyphenyl ring would be unlikely to fit well into the back pocket of a kinase with larger residues in this region, and as such this may well explain the high selectivity of the molecule. However, it should be noted that both VEGFR1 and VEGFR2 also contain valine at the corresponding positions which may therefore explain the moderate activity of 7 at VEGFR2. The urea substituent in the 7-position forms an internal hydrogen bond to the N8 nitrogen of the core and is also involved in a water-mediated interaction with the side chains of Asp641 and Lys514. The importance of this internal hydrogen bond is likely to explain the importance of the urea NH for kinase binding. The electron density for the aminoalkyl substituent in the 2-position is poorly defined suggesting that considerable flexibility exists in this region. This is consistent with the observation that the 
<smiles>CCNC(=O)Nc1nc2nc(NCCCCN(CC)CC)ncc2cc1-c1c(Cl)cccc1Cl</smiles>

\begin{tabular}{|c|c|c|c|c|}
\hline Compound & $\mathbf{4}$ & $\mathbf{5}$ & $\mathbf{6}$ & $\mathbf{7}$ \\
\hline FGFR IC $_{50}(\mu \mathrm{M})$ & 0.048 & 0.051 & 0.033 & 0.026 \\
\hline PDGFR IC $_{50}(\mu \mathrm{M})$ & 0.31 & 0.47 & 0.19 & 15.5 \\
\hline EGFR IC $_{50}(\mu \mathrm{M})$ & 0.24 & 0.15 & 1.26 & $>40$ \\
\hline c-Src IC $_{50}(\mu \mathrm{M})$ & 0.044 & 0.031 & 0.023 & 20.3 \\
\hline
\end{tabular}

Fig. 5 SAR of C2- and C7-substitution

2-aminoalkyl substituent has a greater impact on the physicochemical properties of the molecule than on its biological activity. The SAR identified by the researchers at Parke-Davis during the identification of 7, together with the structural information regarding the binding mode and specific interactions with FGFR, has informed the subsequent work of many groups also looking to identify selective inhibitors of FGFR.

Continued exploration of the scaffold revealed the ability to replace the pyrido [2,3-d]pyrimidine $\mathrm{N} 1$ nitrogen with a $\mathrm{CH}, \mathbf{8}$; an observation that is also consistent with the anticipated binding mode and highlighting the limited contribution of this nitrogen to the overall binding affinity of the scaffold [11]. Interestingly, this modification appears to increase in VEGFR potency. More detailed exploration of the 2-aminoalkyl group confirms that the basic center is not a requirement for biological activity with neutral analogue 9 displaying a similar potency and selectivity profile, although solubility is reduced dramatically. As anticipated from the 
Fig. 6 Structure of 7 bound to FGFR1 (PDB accession code 2FGI) with hydrogen bonds highlighted in magenta

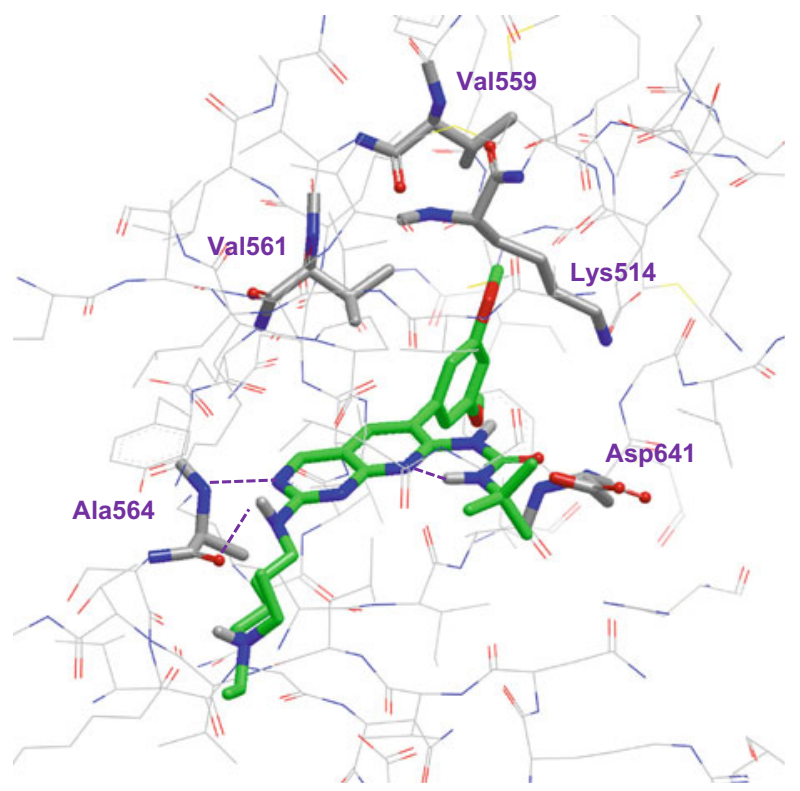

binding mode, removal of the 2-amino $\mathrm{NH}$ results in a significant loss of potency (Fig. 7).

In parallel with the optimization of hit $\mathbf{1}$, the researchers at Parke-Davis also optimized a related pyrido[2,3-d]pyrimidin-7-one hit $\mathbf{1 0}$ with the expectation of identifying kinase inhibitors with differing profiles with respect to inhibitory activity, metabolism, and pharmacokinetic properties [12]. Optimization of this scaffold resulted in the discovery of PD166285 (11), a potent inhibitor of a range of tyrosine kinases (including FGFR, PDGFR, EGFR, and c-Src) which displays excellent physicochemical properties [13].

\subsection{Indolin-2-One-Based FGFR Inhibitors}

The discovery of a series of indolin-2-one compounds possessing a broad kinase inhibition profile (including PDGFR $\beta$, VEGFR2, EGRF, HER-2, and IGF-1R) was reported by Sun et al. from the laboratories of Sugen [14]. The initial SAR was developed against a broad spectrum of kinase inhibition and highlighted the important role the configuration at the C3-position of the indolin-2-one scaffold plays on both the potency and selectivity profile of the molecule. In particular, it was observed that compounds with a 3-[(pyrrolyl)methylidene]indolin-2-one scaffold, such as 12, exist predominantly in the Z-configuration and that these compounds exhibit selectivity for VEGFR2 and PDGFR $\beta$ ( IC $_{50}$ values $0.039,12 \mu \mathrm{M}$, respectively) over EGFR, HER-2, and IGF-1R (all >100 $\mu \mathrm{M}$ ). Elaboration of the 
<smiles>CCN(CC)CCCCNc1cc2nc(NC(=O)NC(C)(C)C)c(-c3cc(OC)cc(OC)c3)cc2cn1</smiles><smiles>Cn1c(=O)c(-c2c(Cl)cccc2Cl)cc2cnc(N)nc21</smiles>

10<smiles>CN(C)CCOc1ccc(Nc2ncc3cc(-c4c(Cl)cccc4Cl)c(=O)n(C)c3n2)cc1</smiles>

11

\begin{tabular}{|c|c|c|c|c|}
\hline Compound & $\mathbf{8}$ & $\mathbf{9}$ & $\mathbf{1 0}$ & $\mathbf{1 1}$ \\
\hline FGFR IC $_{50}(\mu \mathrm{M})$ & 0.060 & 0.052 & 1.3 & 0.043 \\
\hline PDGFR IC $_{50}(\mu \mathrm{M})$ & 18.0 & 23.0 & 4.9 & 0.079 \\
\hline VEGFR IC $_{50}(\mu \mathrm{M})$ & 0.015 & 0.008 & - & - \\
\hline EGFR IC $_{50}(\mu \mathrm{M})$ & - & - & 5.6 & 0.044 \\
\hline c-Src IC & & & & 0.009 \\
\hline
\end{tabular}

Fig. 7 SAR of 1,6-naphthyridine core and pyrido[2,3-d]pyrimidin-7-one core

pyrrolyl motif resulted in the identification of SU5402 (13), a relatively selective inhibitor of VEGFR2 $\left(\mathrm{IC}_{50}=0.02 \mu \mathrm{M}\right)$ and FGFR1 $\left(\mathrm{IC}_{50}=0.03 \mu \mathrm{M}\right)($ Fig. 8).

A crystal structure of SU5402 (13) bound to FGFR1 revealed the indolin-2-one moiety to occupy the region of the binding site normally occupied by the adenosine ring of ATP (albeit that the orientation of the bicyclic ring systems differs dramatically) and that a bidentate hydrogen-bonding interaction with the kinase hinge region is formed from both the indoline $\mathrm{NH}$ and the oxygen of the indoline carbonyl group (Fig. 9). An intramolecular hydrogen bond was observed between the pyrrole NH and the indoline carbonyl oxygen, thus helping favor the optimal Z-configuration. The structure highlights the presence of water molecules near the C5 position of the indolin-2-one ring, perhaps suggestive that hydrophilic substitution may be tolerated at this position. The structure also shows the propionic acid 
Fig. 8 The structure of indolin-2-ones $\mathbf{1 2}$ and $\mathbf{1 3}$

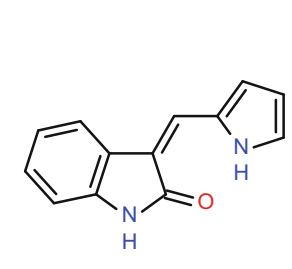

12
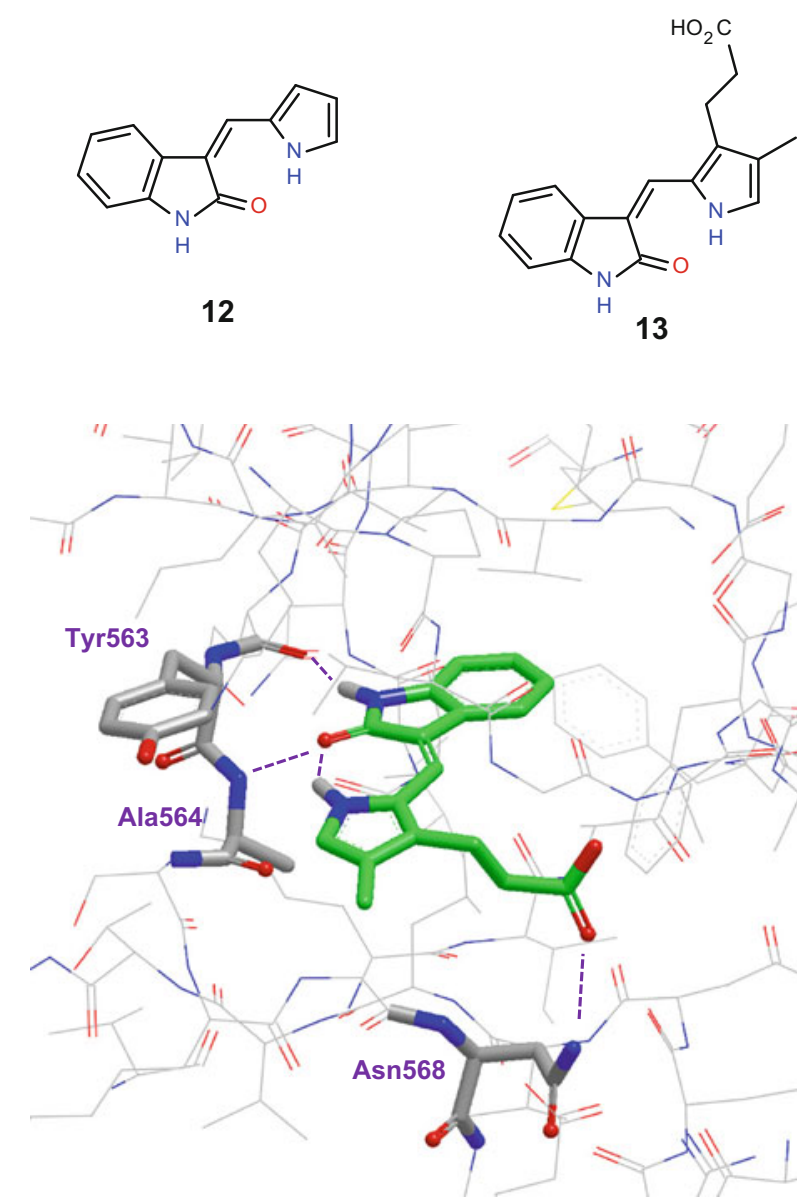

Fig. 9 Structure of $\mathbf{1 3}$ bound to FGFR1 (PDB accession code 1FGI) with hydrogen bonds highlighted in magenta

chain to reach into the ribose binding pocket where it makes an interaction with Asn568 [15].

A comparison of the structure with the published structural data for PD173074 (7) bound to FGFR1 suggested to the authors the possibility to build out from the 6-position of the indolin-2-one ring to access the hydrophobic back pocket of the binding site. These insights resulted in the examination of phenyl substitution in the 6-position of the indolin-2-one ring [16]. Initial investigations resulted in an unexpected loss of potency, such as 14; however, parallel SAR studies conducted on a structurally related start point, exemplified by the PDGFR $\beta$ selective compound SU6668 (15), did suggest that the back pocket could be accessed from this position of the indolin-2-one ring and that improved FGFR1 and VEGFR2 potency could be attained, for example compound 16. Computational modeling suggests that the propionic acid motif in $\mathbf{1 5}$ forms an interaction with a lysine residue rather than the asparagine residue observed for $\mathbf{1 3}$ and the authors speculate that the 
6-phenyl substituent causes a slight movement of the indolin-2-one ring in the binding site resulting in the weakening of the propionic acid/asparagine interaction for one series and strengthening the propionic acid/lysine interaction in the other. As suggested from the crystal structure, hydrophilic substituents were found to be tolerated in the C5 position, exemplified by 17 , and were found to generally enhance FGFR activity compared to VEGFR2 and PDGFR $\beta$ activity (Fig. 10).

Interestingly, throughout the reported SAR investigation, the authors note an apparent disconnect between biochemical potency and cell potency. They postulate that poor cell permeability, related to the physicochemical properties of some of the molecules described, contributes to this observed disconnect.

Further optimization of this scaffold was reported by Kammasud et al. from Mahidol University in Thailand, collaborating with researchers from the Khon Kaen University in Thailand, the University of Tayama in Japan, and the Institut Curie in Orsay, France [17]. This optimization utilized computational docking studies in an attempt to identify more efficient binders. Libraries of virtual compounds were docked into a template constructed from the published crystal structure of PD173074 (7) and ranked based on the calculated docking energies. This

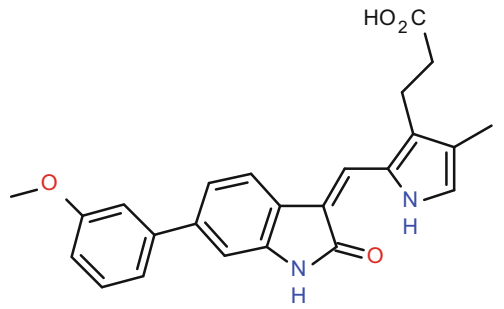

14

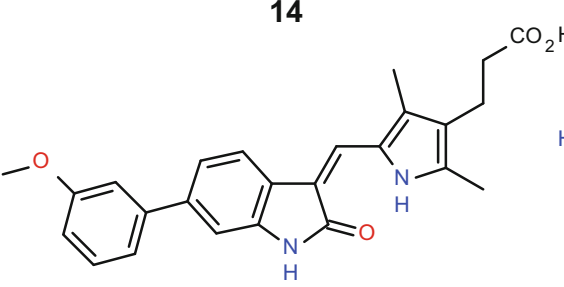

16

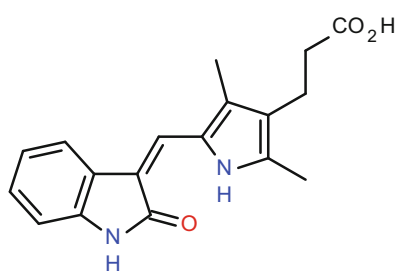

15

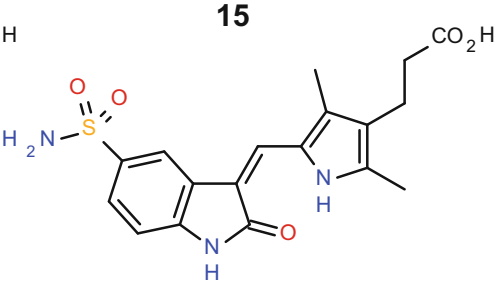

17

\begin{tabular}{|c|c|c|c|c|}
\hline Compound & $\mathbf{1 4}$ & $\mathbf{1 5}$ & $\mathbf{1 6}$ & $\mathbf{1 7}$ \\
\hline FGFR1 IC $50(\mu \mathrm{M})$ & 1.2 & 3.04 & 1.40 & 0.28 \\
\hline VEGFR2 $\mathrm{IC}_{50}(\mu \mathrm{M})$ & 28.3 & 2.43 & 0.30 & 1.26 \\
\hline${\text { PDGFR } \beta \mathrm{IC}_{50}(\mu \mathrm{M})}$ & 0.45 & 0.06 & 0.10 & 1.53 \\
\hline
\end{tabular}

Fig. 10 SAR of indolin-2-one compounds 


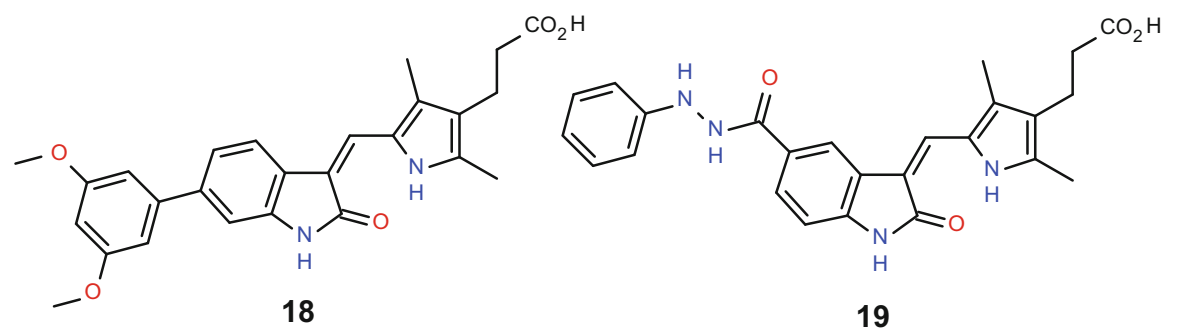

Fig. 11 Structure of NP603 (18) and NP506 (19)

approach identified NP603 (18) as a potential compound of interest, which was subsequently synthesized and found to bind to FGFR1 with moderate potency in a biochemical assay $\left(\mathrm{IC}_{50}=0.52 \mu \mathrm{M}\right)$. Compound 18 showed slightly reduced activity against VEGFR2 and PDGFR $\beta$ in biochemical assays $\left(\mathrm{IC}_{50}\right.$ 's $=0.93$ and $0.78 \mu \mathrm{M}$, respectively) and was inactive against EGFR $\left(\mathrm{IC}_{50}>100 \mu \mathrm{M}\right)$. Unfortunately, the relatively modest activity of $\mathbf{1 8}$ in an antiproliferative HUVEC cell model $\left(\mathrm{IC}_{50}=18.2 \mu \mathrm{M}\right)$, and in an FGF-2-stimulated HUVEC tube-forming assay, precluded the more detailed profiling of this compound. Interestingly, the authors postulate that a 3,5-dicyanophenyl group in the 6-position of the indolin-2-one ring might confer additional potency due to the extended delocalization of the $\pi$-electrons; however, despite the promising docking score, no data are reported for this compound (Fig. 11).

Computational modeling was also used to prioritize the SAR investigations into substitution of the 5-position of the indolin-2-one core. As a result of this in silico approach, NP506 (19) was synthesized and shown to possess good activity against FGFR1, VEGFR2, and PDGFR $\beta$ in biochemical assays $\left(\mathrm{IC}_{50}\right.$ ' $\mathrm{s}=0.10 \mu \mathrm{M}, 0.07 \mu \mathrm{M}$, and $0.04 \mu \mathrm{M}$, respectively) but was less active against $\operatorname{EGFR}\left(\operatorname{IC}_{50}=3.48 \mu \mathrm{M}\right)$ [18]. The proposed binding mode for 19 locates the phenylhydrazine moiety more deeply in to the hydrophobic back pocket compared to the 3,5-dimethoxyphenyl moiety of 18 and forms a $\pi-\pi$ interaction with Phe642. However, despite the improved biochemical potency of 19, little difference is observed between the potency of this compound in a cellular antiproliferation assay compared with $18\left(\mathrm{IC}_{50}=18.2\right.$ and $27.4 \mu \mathrm{M}$, respectively). The authors postulate that the physicochemical properties of $\mathbf{1 9}$ may result in poor cellular permeability. Compound $\mathbf{1 9}$ also appears to show activity against the PI3K/AKT-signaling pathway perhaps indicating that the compound is less selective than $\mathbf{1 8}$. 


\subsection{Benzimidazol-2-Ylhydroquinolin-2-One-Based FGFR Inhibitors}

Renhowe et al. have described work performed within Novartis that resulted in the discovery of a benzimidazol-2-ylhydroquinolin-2-one scaffold [19]. The commercially available compound $\mathbf{2 0}$ was identified as a potent inhibitor of VEGFR2, FGFR1, and PDGFR following a high-throughput screening approach $\left(\mathrm{IC}_{50}\right.$ 's $=0.24$, 0.090 and $0.020 \mu \mathrm{M}$, respectively). However, the poor physicochemical properties of the molecule, in particular the low aqueous solubility, precluded in vivo characterization for this compound and hence optimization of this scaffold was initiated (Fig. 12).

Initial SAR studies revealed the important role of the hydroquinolin-2-one NH and the benzimidazole $\mathrm{NH}$ on binding, with methylation of either one, or of both (21), of these groups resulting in a significant decrease in biochemical activity. The authors rationalize this observation based on molecular modeling studies, which suggest the involvement of both NH groups, along with the hydroquinolin-2-one carbonyl oxygen, in a tridentate donor-acceptor-donor interaction with the hinge region of the kinases. The research also highlighted the requirement for a hydrogen bond donor motif in the C4-position of the hydroquinolin-2-one ring (comparing 20 and 23 with compound 22). The authors postulate that the presence of a hydrogen bond donor in this position allows the formation of an intramolecular hydrogen bond with the benzimidazole motif thereby maintaining a coplanar arrangement of the rings while simultaneously favoring the benzimidazole tautomeric form required for the tridentate interaction with the kinase hinge. Basic functionality could be appended to this position and was unexpectedly found to modulate the kinase selectivity profile of the molecules in addition to the anticipated impact on physicochemical properties. In particular, large basic substituents, such as the aminoquinuclidine in $\mathbf{2 4}$, resulted in compounds with significantly increased activity against PDGFR compared to VEGFR and FGFR. Such compounds also showed considerable activity against other kinases, including CHK-1 and GSK-3. However, given the desire to identify selective inhibitors of tyrosine kinases, the authors conclude that the 4-amino substituent was optimal for the program (Fig. 13).

Modulation of the physicochemical properties without undue impact on the kinase selectivity profile was achieved by modifying the periphery of the molecule.

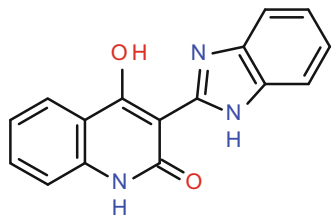

20

Fig. 12 Structure of screening hit 20 
<smiles>Cn1c(-c2c(O)c3ccccc3n(C)c2=O)nc2ccccc21</smiles>

21<smiles>Nc1c(-c2nc3ccccc3[nH]2)c(=O)[nH]c2ccccc12</smiles>

23<smiles>O=c1[nH]c2ccccc2cc1-c1nc2ccccc2[nH]1</smiles>

22<smiles>O=c1[nH]c2ccccc2c(N[C@@H]2CN3CCC2CC3)c1-c1nc2ccccc2[nH]1</smiles>

24

\begin{tabular}{|c|c|c|c|c|}
\hline Compound & $\mathbf{2 1}$ & $\mathbf{2 2}$ & $\mathbf{2 3}$ & $\mathbf{2 4}$ \\
\hline FGFR1 IC $_{50}(\mu \mathrm{M})$ & $>25$ & 0.39 & 0.030 & 0.19 \\
\hline${\text { PDGFR } \beta \mathrm{IC}_{50}(\mu \mathrm{M})}$ & $>25$ & 0.070 & 0.010 & 0.0002 \\
\hline VEGFR2 IC & & & & \\
\hline
\end{tabular}

Fig. 13 SAR of the hydroquinolin-2-one scaffold

A wide range of solubilizing groups could be incorporated on the benzimidazole ring with substitution in the 5-position of this ring appearing optimal, exemplified by $\mathbf{2 5}$ and 26. The observation that both acidic and basic functionality was tolerated in this position with little impact on kinase selectivity (data not shown) led the authors to postulate that substitution at this position allows access to a region of the protein which is exposed to solvent. Activity in cellular systems appears improved for compounds in which the basic substituent has a $\mathrm{p} K_{a}$ in the range of 7-9, and the $N$-methylpiperazine motif in particular is reported to possess a good balance of potency and physicochemical properties. Final optimization of the scaffold focused on substituents on the phenyl ring of the hydroquinolin-2-one core. Small electrondonating groups were tolerated in the 5-,6-, and 7-positions of the hydroquinolin-2one ring, such as $\mathbf{2 7}$ and $\mathbf{2 8}$, but larger substituents could be accommodated in the 5-position of the hydroquinolin-2-one ring only. Substitution of any type was not tolerated in the 8-position of the hydroquinolin-2-one ring, presumably due to the substituent interfering with the kinase hinge interaction. Although substitution on this ring generally resulted in compounds with increased activity for PDGFR over FGFR and VEGFR, such as 28, the authors identified that compound $\mathbf{2 7}$ possessed a more balanced profile and thus selected this compound for further profiling. 
Compound 27 has subsequently been referred to as TKI-258, CHIR-258, and eventually as dovitinib (Fig. 14).

In addition to being a potent inhibitor of FGFR1, PDGFR $\beta$, and VEGFR2 in biochemical assays, dovitinib (27) also inhibits VEGFR1 and 3, FGFR3, c-Kit, CSF1R, and Flt3 with $\mathrm{IC}_{50}$ 's ranging between 0.001 and $0.036 \mu \mathrm{M}$. It potently inhibits the phosphorylation of FGFR1, VEGFR2, and PDGFR $\beta$ in cells $\left(\mathrm{EC}_{50}\right.$ 's $=0.166 \mu \mathrm{M}$, $0.046 \mu \mathrm{M}$, and $0.051 \mu \mathrm{M}$, respectively) [20]. Dovitinib (27) shows increased aqueous solubility and attractive pharmacokinetic properties with good oral bioavailability ( $>70 \%$ in mice and rat), moderate to high clearance, and a large volume of distribution resulting in a terminal half-life of approximately $3 \mathrm{~h}$. Dovitinib (27) shows potent inhibition of bFGF-driven angiogenesis in a mouse Matrigel model of neovascularization and tumor regression in both KM12L4a and HCT116 xenograft models at doses $>60 \mathrm{mg} / \mathrm{kg}$. The observed efficacy is associated with a significant reduction of phosphorylated PDGFR $\beta$ and a reduction of phosphorylation of the downstream protein ERK in the tumor cells. Based on the preclinical data, dovitinib (27) has

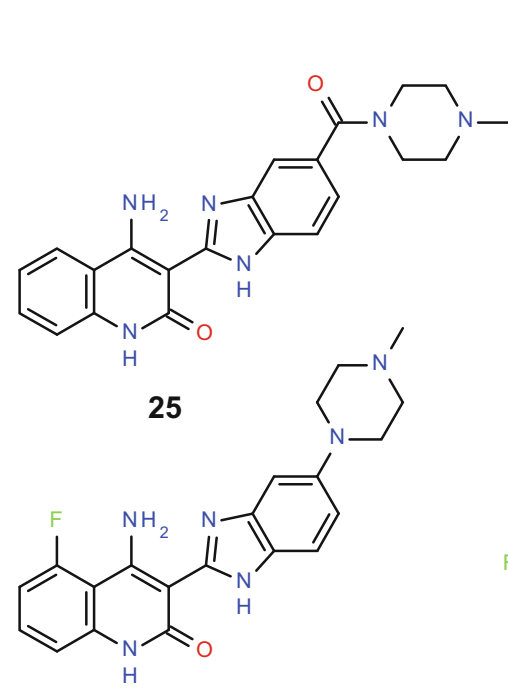

27

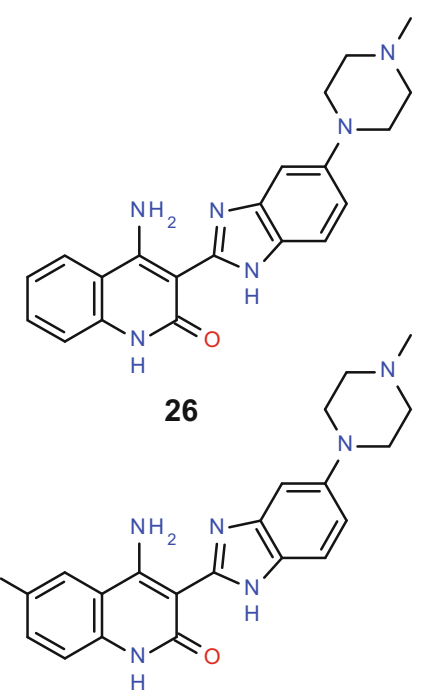

28

\begin{tabular}{|c|c|c|c|c|}
\hline Compound & $\mathbf{2 5}$ & $\mathbf{2 6}$ & $\mathbf{2 7}$ & $\mathbf{2 8}$ \\
\hline FGFR1 IC $_{50}(\mu \mathrm{M})$ & 0.010 & 0.009 & 0.011 & 0.040 \\
\hline${\text { PDGFR } \beta \mathrm{IC}_{50}(\mu \mathrm{M})}$ & 0.0009 & 0.002 & 0.005 & 0.001 \\
\hline VEGFR2 IC $_{50}(\mu \mathrm{M})$ & 0.026 & 0.042 & 0.065 & 0.078 \\
\hline
\end{tabular}

Fig. 14 SAR of the hydroquinolin-2-one scaffold 
been described as a multi-targeted growth factor receptor kinase inhibitor and has been studied in a number of clinical studies, including a phase I/II study in patients with advanced melanoma; a phase II study in patients with previously treated, metastatic, HER2-negative breast cancer; and a phase II study in combination with fulvestrant in postmenopausal, HER2-negative/HR-positive advanced breast cancer patients.

\subsection{Pyrimidinyl Ureas as FGFR Inhibitors}

In parallel with the development of dovitinib (27), Guagnano et al. describe complementary work within the Novartis laboratories designed to identify an inhibitor of FGFR with increased selectivity over VEGFR and PDGFR [21]. The authors postulate that the identification of such a compound would not only aid the understanding of the role of FGFR in cancer but may also provide a superior therapeutic agent with a potentially more favorable toxicity profile compared to more promiscuous drugs. The approach adopted by the authors built on a strategy successfully employed within Novartis for the identification of a range of novel kinase inhibitors and relies on the use of stable "pseudo" ring systems (formed by intramolecular hydrogen-bonding interactions) to replace the cyclic structures of known kinase inhibitors. The authors utilized ab initio calculations on a model system to support the hypothesis that a pyrimidine-urea motif would preferentially adopt a pseudo cyclic conformation (B) in which the pyrimidine and the methyl substituents adopt a cis relationship over an open trans conformation (A) (Fig. 15) [22]. A search of the Cambridge Structural Database identified seven examples of crystal structures where this motif is present and in all cases the structural data supported the presence of the cis conformation $\mathbf{B}$.

The pyrido[2,3-d]pyrimidin-7-one scaffold, developed within Parke-Davis during the optimization of PD166285 (11), was selected as an appropriate start point resulting in the synthesis and evaluation of pyrimidinyl urea 29. Compound 29 showed activity against a broad range of kinases, including FGFR1 $\left(\mathrm{IC}_{50}=0.57 \mu \mathrm{M}\right)$; interestingly, the activity was limited to kinases with small gatekeeper residues. Modeling of $\mathbf{2 9}$ based on the known binding mode of the pyrido[2,3-d]pyrimidin-7one scaffold in c-Abl suggests the 2,6-dichlorophenyl motif binds to the hydrophobic back pocket with a high degree of complimentarily and that a steric clash would be apparent in this region should the kinase have a large gatekeeper residue. The reported SAR and structure of 7 bound to FGFR1 led the authors to postulate that

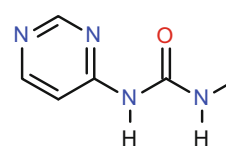

A

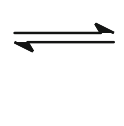

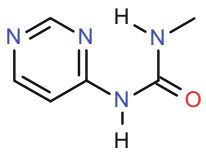

B

Fig. 15 Possible conformations for pyrimidinyl urea motif 


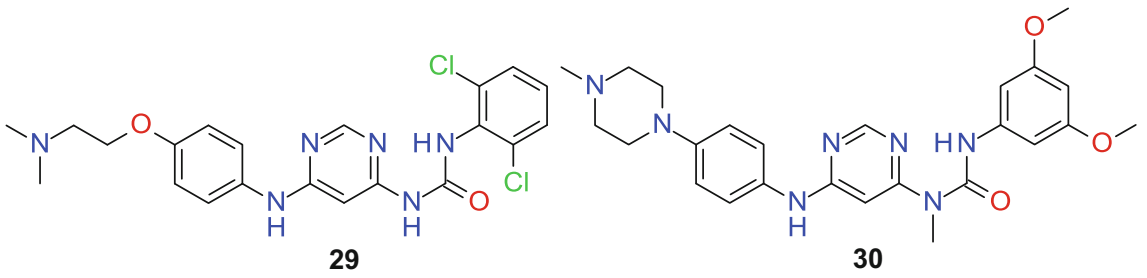

Fig. 16 Structure of pyrimidinyl ureas 29 and $\mathbf{3 0}$

improved FGFR potency and selectivity might be achieved through the incorporation of a 3,5-dimethoxyphenyl motif into the pyrimidinyl urea scaffold and resulted in the identification of compound $\mathbf{3 0}$ (Fig. 16).

Compound 30 was a moderately potent inhibitor of FGFR3 in both a biochemical assay using constitutively active FGFR3-K650E kinase $\left(\mathrm{IC}_{50}=0.505 \mu \mathrm{M}\right)$ and a cell assay using an FGFR3-dependent $\mathrm{BaF} 3$ cell line $\left(\mathrm{IC}_{50}=1.5 \mu \mathrm{M}\right)$. A homology model of FGFR3 was also constructed to aid compound design. The authors appreciated the requirement for the 3,5-dimethoxyphenyl ring to adopt an orthogonal orientation with respect to the pyrimidine ring to best compliment the hydrophobic back pocket and so focused on molecular conformational. Ab initio calculations predict that 7 is likely to have a torsional angle of $127^{\circ}$ between the 3,5-dimethoxyphenyl ring and the pyrido[2,3-d]pyrimidine ring when in a relaxed conformation in water and that an energy penalty of $0.5 \mathrm{kcal} / \mathrm{mol}$ would be required to access the perpendicular conformation observed in the binding mode (tortional angle of $\sim 90^{\circ}$ ). In contrast, the 3,5-dimethoxyphenyl ring in compound $\mathbf{3 0}$ is predicted to be coplanar with the pyrimidinyl urea motif in the relaxed conformation (torsional angle of $180^{\circ}$ ) with an energy penalty of $1.5 \mathrm{kcal} / \mathrm{mol}$ required to access the postulated binding conformation. This energy difference arises from the higher deconjugation energy penalty for compound $\mathbf{3 0}$ compared to 7, and the hypothesis is consistent with the observed reduction in potency. The introduction of ortho-substituents to the 3,5-dimethoxyphenyl ring was anticipated to reduce the deconjugation energy, and compound 31, bearing diortho-substitution, was predicted to have a torsional angle of $109^{\circ}$ in the relaxed conformation with an energy penalty of only $0.1 \mathrm{kcal} / \mathrm{mol}$ to access the postulated binding conformation. Compound 31 does indeed show significantly increased potency in both biochemical and cell assays. Modeling of $\mathbf{3 1}$ in the FGFR3 homology model suggests a tridentate interaction with the kinase hinge between the anilino $\mathrm{NH}$, the adjacent pyrimidine nitrogen, and the pyrimidine $\mathrm{C}(2)-\mathrm{H}$ as well as the potential for a watermediated interaction between the urea carbonyl and the side chain of Lys508 (Lys514 in FGFR1). The optimized fit of the tetra-substituted phenyl ring was predicted to result in productive interactions between the methoxy substituent and Asp635 (Asp641 in FGFR1) as well as favorable hydrophobic interactions between the two chlorine atoms and the Val555 and Ala634 residues (Val561 and Ala640 in FGFR1). Interestingly, the latter residue is replaced by a larger cysteine in 
VEGFR2, and the authors speculate that as a result of increased steric congestion an energy penalty might be incurred when the compound binds to VEGFR2.

The methyl group on the urea nitrogen can be replaced with either hydrogen or an ethyl substituent with little impact on potency, suggesting that there is minimal interaction between this substituent and the protein. The anilino substituent was postulated to occupy the solvent channel of the kinase and, as such, was anticipated to provide a handle to modulate the physicochemical and pharmacokinetic properties of the molecule. A range of anilino substituents could be tolerated, resulting in potent compounds such as $\mathbf{3 2}$ and 33. Evaluation of compounds in a panel of cytochrome P450 (CYP450) drug-metabolizing enzymes highlighted the potential for many compounds from this scaffold to act as inhibitors. CYP450 inhibitors can alter the metabolism and exposure of coadministered compounds, which may in turn result in toxicity. Interestingly, compound $\mathbf{3 1}$ did not show inhibitory activity against any of the CYP450 enzymes tested $\left(\mathrm{IC}_{50}>10 \mu \mathrm{M}\right)$ and was hence selected for further profiling and given the corporate identifier BGJ-398. A crystal structure of BGJ-398 (31) bound to FGFR1 was obtained and found to validate the putative interactions suggested by the homology model of FGFR3 (Figs. 17 and 18).

More thorough testing revealed that $\mathbf{3 1}$ was an exceptionally potent inhibitor of FGFR1-3 ( IC $_{50} \sim 0.001 \mu \mathrm{M}$ ) but was a significantly less potent inhibitor of FGFR4 $\left(\mathrm{IC}_{50}=0.060 \mu \mathrm{M}\right)$ and VEGFR2 $\left(\mathrm{IC}_{50}=0.18 \mu \mathrm{M}\right)$. Compound 31 was largely

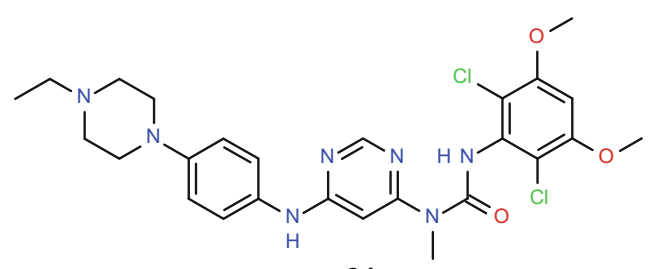

31<smiles>COc1cc(OC)c(Cl)c(NC(=O)N(C)c2cc(Nc3cccc(CN(C)C)c3)ncn2)c1Cl</smiles>

\begin{tabular}{|c|c|c|c|}
\hline Compound & $\mathbf{3 1}$ & $\mathbf{3 2}$ & $\mathbf{3 3}$ \\
\hline FGFR3-K650E IC $_{50}(\mu \mathrm{M})$ & 0.005 & 0.009 & 0.019 \\
\hline BaF3-TEL-FGFR3 IC $_{50}(\mu \mathrm{M})$ & 0.002 & 0.002 & 0.011 \\
\hline
\end{tabular}

Fig. 17 SAR of pyrimidinyl ureas 


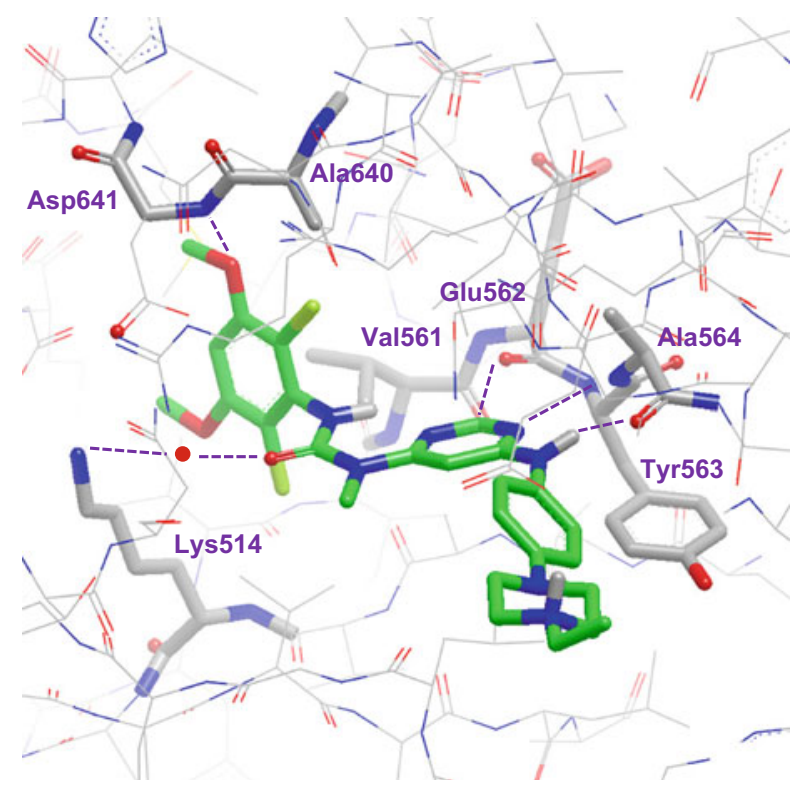

Fig. 18 Structure of $\mathbf{3 1}$ bound to FGFR1 (PDB accession code 3TT0) with hydrogen bonds highlighted in magenta

inactive when tested against a panel of 76 kinases with only KIT and LYN showing $\mathrm{IC}_{50}$ values below $1 \mu \mathrm{M}$. When tested against a panel of $31, \mathrm{BaF} 3$ cell line $\mathbf{3 1}$ was highly potent in the FGFR1-3 lines $\left(\mathrm{IC}_{50} \sim 0.001 \mu \mathrm{M}\right.$ ) but was approximately 400 times less active against VEGFR2 lines and inactive against most other lines. The compound displays high clearance and high volume of distribution in mouse and rat with moderate to good bioavailability and some evidence of increased exposure in tumor tissue compared to plasma. Efficacy was observed in orthotopic mouse xenograft models and subcutaneous rat xenograft models, and this was associated with in vivo knockdown of pFRS2 and pMAPK. It also inhibited bFGF-stimulated angiogenesis in a murine agar chamber model but had no effect on VEGF-stimulated angiogenesis, further demonstrating the selectivity for FGFR over VEGFR. Compound $\mathbf{3 1}$ was evaluated in a phase I study in patients with advanced solid tumors and is currently undergoing evaluation phase II trials in patients with solid tumors, glioblastoma multiforme, and melanoma.

\subsection{Pyrazolylaminopyrimidines and Pyrazolylbenzamides as FGFR Inhibitors}

Leach et al. have reported the early work undertaken with the laboratories of AstraZeneca toward the identification of selective FGFR inhibitors [23]. A 
pyrazolylaminopyrimidine scaffold, exemplified by $\mathbf{3 4}$, was identified from routine kinase selectivity screening as displaying increased potency against FGFR1 and VEGFR2 compared to IGF-1R, the biological target against which the scaffold had originally been optimized. A crystal structure of compound $\mathbf{3 4}$ bound into FGFR1 was obtained, and the authors note the high degree of similarity of the observed protein structure with those reported by other groups (Fig. 19). The equipotent nature of 34 against both FGFR1 and VEGFR2 suggested that binding sites of the two proteins are likely to be highly similar. The authors constructed a "map" of the binding site using the sequence alignment of the two proteins and used this map to identify the position of sequence differences between the two proteins within the binding site. They then postulate that by designing molecules which occupy these areas, it may be possible to exploit these differences to achieve selectivity. In particular, this highlights the Ala640 residue in FGFR1, which is replaced by Cys1043 in VEGFR2, and they note that the side chain of the residue lies in a constricted indentation at the base of the ATP pocket. The authors refer to this region as the "pit" and suggest that inhibitors that are able to effectively target this region may show selectivity for FGFR over VEGFR. When bound into FGFR1 compound 34 appears to make a tridentate donor-acceptor-donor interaction between the three nitrogens in the aminopyrazolyl motif and the kinase hinge. Two conformations are observed for the aminoethylpyridine motif illustrating the flexible nature of the aminoethyl linker, and while one of the observed conformations does position the pyridyl ring in the vicinity of the "pit," the authors speculate that the compound is sufficiently flexible to adapt to the VEGFR binding site, thus explaining the apparent lack of selectivity.

Fig. 19 Structure of $\mathbf{3 4}$ bound to FGFR1 (PDB accession code 4F63) with hydrogen bonds highlighted in magenta

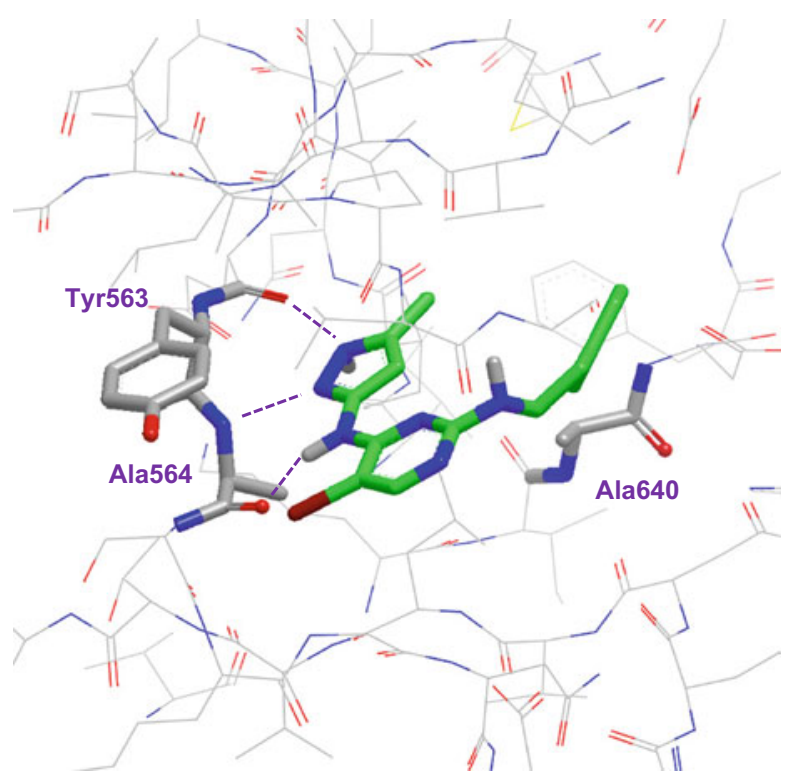


Compounds with more rigid linkers in this region of the molecule, such as $\mathbf{3 5}$, do show a preference for binding to FGFR suggesting that the "pit" region can indeed be targeted to achieve selectivity. The crystal structure of a more soluble analogue of 35 bound into FGFR1 was obtained which showed the methyl of the isoxazole to be directed at Ala640 further supporting the hypothesis (Fig. 20).

Exploration of different regions of the molecule quickly established that the bromine could be removed with little impact on potency, 36. This change is associated with a reduction in $\log \mathrm{P}$ of approximately one unit, thereby demonstrating improved binding efficiency as measured by lipophilicity ligand efficiency (LLE). Comparison of the structures of both $\mathbf{3 4}$ and PD173074 (7) bound to FGFR1 suggested an opportunity to target the hydrophobic back pocket of the ATP-binding site by building from the 5-position of the pyrazole ring. The incorporation of a 3,5-dimethyoxyphenyl ring, known to have high complementarity to the back pocket in other scaffolds, linked to the pyrazole with a two-carbon spacer, resulted in compound $\mathbf{3 7}$ which shows a dramatic improvement in FGFR1 potency while retaining good selectivity over VEGFR2. However, despite the promising profile of 37, the lipophilic nature of the compound resulted in poor aqueous

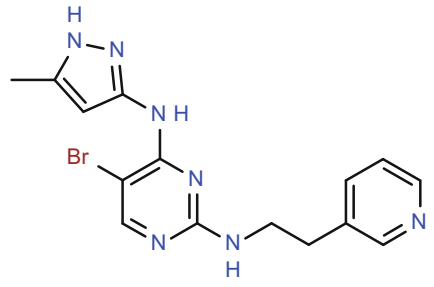

34

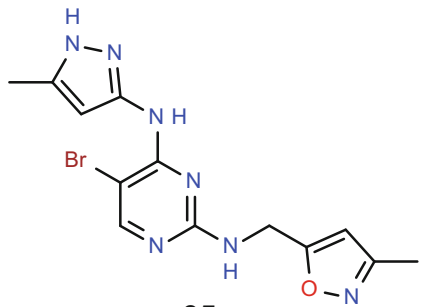

35

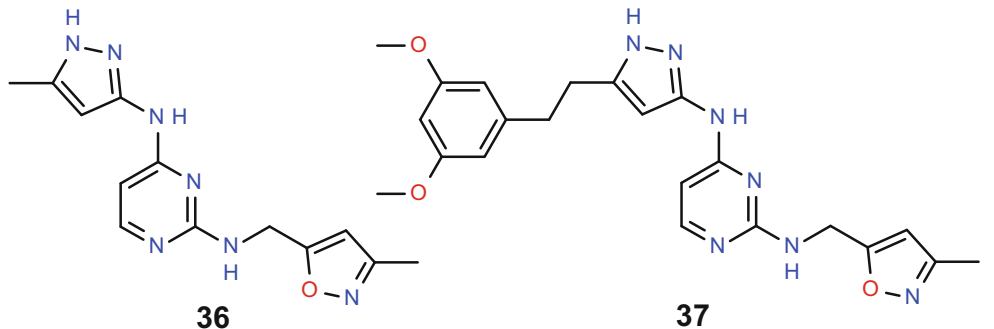

\begin{tabular}{|c|c|c|c|c|}
\hline Compound & $\mathbf{3 4}$ & $\mathbf{3 5}$ & $\mathbf{3 6}$ & $\mathbf{3 7}$ \\
\hline FGFR1 IC $_{50}(\mu \mathrm{M})$ & 0.54 & 0.069 & 0.079 & 0.0018 \\
\hline VEGFR2 IC & & & & \\
\hline IGF-1R IC & & & & \\
\hline & 0.59 & 0.68 & 1.0 & 0.126 \\
\hline
\end{tabular}

Fig. 20 SAR of pyrazolylaminopyrimidines 
solubility $(0.6 \mu \mathrm{M})$ and was felt to preclude the in vivo characterization of the compound.

The continued optimization of the scaffold within AstraZeneca has been described by Thomas et al. [24]. The requirement to identify compounds with reduced lipophilicity was appreciated, and the researchers looked to introduce a broad range of structural changes to the scaffold while maintaining the aminopyrazole hinge binder motif. These studies resulted in the identification of the pyrazolylbenzamide scaffold, exemplified by $\mathbf{3 8}$. Compound $\mathbf{3 8}$ showed promising activity against FGFR1 in a biochemical assay and inhibited the phosphorylation of FGFR in Cos-1 cells transfected with FGFR1. Once again significant improvements in potency and selectivity were observed by successfully targeting the hydrophobic back pocket, for example, compound 39. Attempts to further optimize this region of the molecule were largely unsuccessful, thereby suggesting that the identified substituent was achieving an optimal interaction with the hydrophobic back pocket (Fig. 21).

A crystal structure of compound 39 bound in to FGFR1 showed the $\mathrm{N}$ methylpiperazinyl unit to be situated in the solvent channel of the kinase and thus<smiles>COc1cc(CCc2cc(NC(=O)c3ccc(N4CCN(C)CC4)cc3)[nH]n2)cc(CCc2cc(NC(=O)c3ccc(N4CCNCC4)cc3)n[nH]2)c1</smiles>

\begin{tabular}{|c|c|c|c|c|}
\hline Compound & $\mathbf{3 8}$ & $\mathbf{3 9}$ & $\mathbf{4 0}$ & $\mathbf{4 1}$ \\
\hline FGFR1 IC $_{50}(\mu \mathrm{M})$ & 0.066 & 0.0007 & 0.0009 & 0.0002 \\
\hline Cos-1 pFGFR1 IC $_{50}(\mu \mathrm{M})$ & 0.61 & 0.019 & 0.017 & 0.013 \\
\hline
\end{tabular}

Fig. 21 SAR of pyrazolylbenzamide scaffold 
might provide an opportunity to modulate physicochemical and pharmacokinetic properties. More detailed profiling of $\mathbf{3 9}$ revealed high clearance of the compound in rat hepatocyte incubations $\left(\mathrm{Cl}_{\mathrm{int}}=60 \mu \mathrm{L} / \mathrm{min} / 10^{6}\right.$ cells $)$ and in rat in vivo pharmacokinetic studies $(\mathrm{Cl}=46 \mathrm{~mL} / \mathrm{min} / \mathrm{kg})$. Metabolite identification studies highlighted significant $\mathrm{N}$-demethylation and $\mathrm{N}$-oxidation of the $\mathrm{N}$-methylpiperazinyl functionality. The high clearance of the compound, driven by metabolism of the $\mathrm{N}$ methylpiperazinyl motif, limited the oral bioavailability of the compound. The strategies adopted to lower clearance included the removal of the $N$-methyl on the piperazine ring as well as reducing the potential of the piperazine to undergo both $N$-oxidation and $N$-dealkylation by increasing the $\mathrm{p} K_{a}$, thereby increasing the fraction of the basic center existing in a protonated form. Removal of the $N$-methyl group, 40, was well tolerated and did result in a reduction of clearance in both in vitro rat hepatocyte incubations $\left(\mathrm{Cl}_{\text {int }}=12 \mu \mathrm{L} / \mathrm{min} / 10^{6}\right.$ cells $)$ and in rat in vivo pharmacokinetic studies $(\mathrm{Cl}=23 \mathrm{~mL} / \mathrm{min} / \mathrm{kg})$; however, oral bioavailability in rat was low (3\%) presumably due to compromized permeability. The optimization goal was therefore to balance reduced clearance with acceptable permeability. The introduction of methyl groups to sterically "mask" the hydrogen bond donor, while concurrently increasing lipophilicity, resulted in the discovery of compound 41, subsequently given the corporate identifier AZD4547, which retains excellent potency against FGFR1 in biochemical and cell assays while displaying low clearance in in vitro rat hepatocyte incubations $\left(\mathrm{Cl}_{\text {int }}=11 \mu \mathrm{L} / \mathrm{min} / 10^{6}\right.$ cells $)$ and in rat in vivo pharmacokinetic studies $(\mathrm{Cl}=16 \mathrm{~mL} / \mathrm{min} / \mathrm{kg})$ and good oral bioavailability in rat $(54 \%)$. Gavine et al. report on the detailed pharmacological profiling of AZD4547 (41) and show the compound to be an extremely potent inhibitor of FGFR1-3 in biochemical assays $\left(\mathrm{IC}_{50}{ }^{\prime} \mathrm{s}=0.0002 \mu \mathrm{M}, 0.0025 \mu \mathrm{M}\right.$ and $0.0018 \mu \mathrm{M}$, respectively) but less active against FGFR4 $\left(\mathrm{IC}_{50}=0.165 \mu \mathrm{M}\right)$. A similar profile was observed when looking at the inhibition of phosphorylation of FGFR in Cos-1 cells transfected with FGFR1-4 $\left(\mathrm{IC}_{50}\right.$ 's $=0.013 \mu \mathrm{M}, 0.002 \mu \mathrm{M}, 0.040 \mu \mathrm{M}$ and $0.142 \mu \mathrm{M}$, respectively). AZD4547 (41) showed reduced activity for the inhibition of phosphorylation of VEGFR2 in HUVEC cells $\left(\mathrm{IC}_{50}=0.258 \mu \mathrm{M}\right)$ and showed excellent selectivity when tested against a broad panel of kinases. AZD4547 (41) has potent in vitro antiproliferative effects on tumor cell lines with dysregulated FGFR expression, such as the FGFR3 driven KMS11 cell line, but was inactive in over 100 additional tumor cell lines. This result is believed to indicate that the antiproliferative effects observed are driven by FGFR inhibition rather than any nonspecific cytotoxicity. AZD4547 (41) showed dose proportional antitumor efficacy in KMS11 xenograft models with concurrent pharmacodynamic modulation of FGFR phosphorylation. AZD4547 (41) did not induce any significant changes in blood pressure in conscious telemetered rats at in vivo exposure levels equivalent to those observed to give efficacy in mouse xenograft models. This observation supports the suggestion that at these efficacious doses there is no significant in vivo activity against VEGFR2 [25]. At the time of writing, AZD4547 (41) was being evaluated in phase II clinical trials in patients with solid tumors. 


\subsection{Indazoles as FGFR Inhibitors}

Zhoa et al. have reported the discovery of a potent and selective inhibitor of FGFR from the laboratories of Eli-Lilly and Company, LY2874455 (42). Compound 42 is based on a novel indazole scaffold [26]. While the detailed SAR investigations which result in the discovery of $\mathbf{4 2}$ have yet to be released, a binding mode of the compound in a homology model of FGFR3 has been proposed based on crystal structures of close analogues bound to an FGFR3 construct. The proposed binding mode appears to show the indazole motif forming a key bidentate interaction with the kinase hinge region, while the 5-(1-(3,5-dichloropyridin-4-yl)ethoxy) substituent appears to head toward the region of the ATP-binding site previously described as the "pit" and makes an interaction between the pyridinyl nitrogen and the protein. The 2-vinylpyrazolyl motif appears to be positioned in the solvent channel and therefore may have provided the researchers with an opportunity to modulate physicochemical and pharmacokinetic properties. In the binding mode presented, the molecule does not appear to exploit the hydrophobic back pocket which has been a common feature in many of the previously reported selective FGFR inhibitors (Fig. 22).

LY2874455 (42) is reported to inhibit all four isoforms of FGFR to a similar degree in a biochemical assay $\left(\mathrm{IC}_{50}\right.$ 's $=0.0028 \mu \mathrm{M}, 0.0026 \mu \mathrm{M}, 0.0064 \mu \mathrm{M}$, and $0.006 \mu \mathrm{M}$, for FGFR $1-4$, respectively), in contrast to many of the selective FGFR inhibitors reported that show a preference for FGFR1-3. However, 42 is also a potent inhibitor of VEGFR2 in biochemical assays $\left(\mathrm{IC}_{50}=0.007 \mu \mathrm{M}\right)$. The authors state that the lack of high quality antibodies against pFGFRs has hampered their attempts to measure the impact of $\mathbf{4 2}$ on the phosphorylation of the individual FGFR isoforms in cellular systems. However, the compound was shown to inhibit the FGF2- and FGF9-stimulated phosphorylation of ERK in HUVEC and RT-112 cells (average $\mathrm{IC}_{50}$ between 0.3 and $0.8 \mathrm{nM}$ ) as well as showing potent antiproliferative effects in the FGFR3 driven KMS11 and OPM-2 cell lines $\left(\mathrm{IC}_{50}\right.$ 's $=0.57$ and $1.0 \mathrm{nM}$, respectively). LY2874455 (42) inhibits both FGF2and VEGF-induced tube-forming activities in an assay $\left(\mathrm{IC}_{50}\right.$ 's $=0.0006$ and $0.0036 \mu \mathrm{M}$, respectively). A similar preference (six- to ninefold) for $\mathbf{4 2}$ to inhibit FGF-induced signaling in vivo over VEGF-induced signaling was observed in an

Fig. 22 Structure of LY2874455

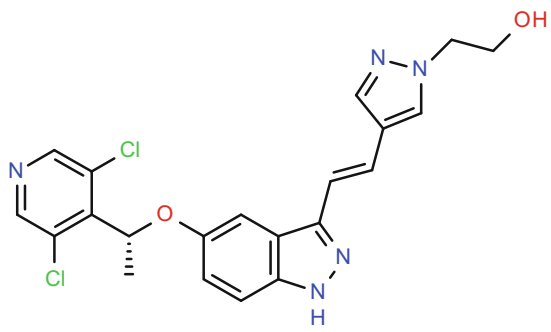


IVTI assay to measure VEGFR-2 phosphorylation in the heart tissues of mice, suggesting a potential margin between FGFR-mediated effects and VEGFRmediated effects exists in vivo. Compound $\mathbf{4 2}$ was reported to cause a significant regression of tumor growth in RT-112, SNU-16, and OPM-2 tumor xenograft models at doses of $3 \mathrm{mg} / \mathrm{kg}$ bid. At the time of writing, 42 had now completed a phase I clinical trial in patients with advanced cancer.

\subsection{Imidazopyridine-Based Inhibitors of FGFR}

Astex Therapeutics has also developed a series of selective FGFR inhibitors. Squires et al. have reported the use of fragment screening, using a combination of nuclear magnetic resonance spectroscopy, thermal denaturation, and X-ray crystallography, to identify low-molecular-weight hits with good binding affinity [27]. This approach resulted in the identification of compound 43, which shows relatively low potency against FGFR3 in a biochemical assay $\left(\mathrm{IC}_{50}=120 \mu \mathrm{M}\right)$. However, when the size of $\mathbf{4 3}$ is taken into account using a parameter such as ligand efficiency, the compound can be seen to bind to FGFR3 with an encouraging efficiency of $0.38 \mathrm{kcal} /$ heavy atom. The crystal structure of $\mathbf{4 3}$ bound to FGFR1 highlighted a single hydrogen-bonding interaction between the imidazopyridine N1 and the backbone $\mathrm{NH}$ of Ala564 in the hinge region of the kinase. The binding mode of $\mathbf{4 3}$ also suggested the opportunity to replace the 3-chloro substituent with an aromatic ring thereby allowing the possibility of interactions with the side chain of Asp641 as well as with Ala640. The binding mode also suggested that 7-substitution would be more optimal than 6-substitution. The authors appreciated that interaction with Ala640 may result in improved selectivity, especially against VEGFR2, which possesses a larger residue in this position (Fig. 23).<smiles>COC(=O)c1ccc2ncc(Cl)n2c1</smiles>

43<smiles>Cc1nnc(-c2ccn3c(-c4cccc(NC(=O)NCC(F)(F)F)c4)cnc3c2)o1</smiles>

Fig. 23 Structure of imidazopyridine FGFR inhibitors 
Although detailed SAR investigations for this scaffold have yet to be published, the structure-based design resulted in the identification of urea-containing compounds, such as 44, which showed good potency against FGFR1-4 $\left(\mathrm{IC}_{50}\right.$ 's $=0.013 \mu \mathrm{M}$, $0.033 \mu \mathrm{M}, 0.003 \mu \mathrm{M}$, and $0.034 \mu \mathrm{M}$, respectively) and moderate selectivity over VEGFR1-3 $\left(\mathrm{IC}_{50}\right.$ 's $=0.013 \mu \mathrm{M}, 0.100 \mu \mathrm{M}$, and $0.068 \mu \mathrm{M}$, respectively). A crystal structure of $\mathbf{4 4}$ bound into FGFR1 highlighted good surface complementarity of the 7-aryl substituent with the protein and also indicated that the urea group forms an interaction between the two urea NHs and the carboxylate of Asp641. The urea carbonyl also appears to be involved in a water-mediated interaction with the side chain of Arg627. Interestingly, the authors note that the positioning of Arg627 is shifted with respect to its position in other FGFR1 structures. The importance of the urea group on both FGFR potency and selectivity is stated to be apparent from the detailed SAR (data not disclosed), and the authors speculate that the unusual positioning of Arg627 may contribute to the selectivity observed. Further optimization of the scaffold, playing particular attention to the reduction of lipophilicity, resulted in the identification of compound $\mathbf{4 5}$. Compound 45 shows good potency against FGFR1-4 ( $\mathrm{IC}_{50}$ 's $=0.078 \mu \mathrm{M}, 0.066 \mu \mathrm{M}, 0.015 \mu \mathrm{M}$, and $0.094 \mu \mathrm{M}$, respectively) and selectivity over VEGFR1-3 ( $\mathrm{IC}_{50}$ 's $=0.44 \mu \mathrm{M}, 0.38 \mu \mathrm{M}$, and $0.32 \mu \mathrm{M}$, respectively). Compounds $\mathbf{4 4}$ and $\mathbf{4 5}$ both show antiproliferative effects in BaF3 cell lines engineered to express constitutively active forms of FGFR1, 3, and 4 and were also shown to inhibit the phosphorylation of FGFR3 in KMS11 cells. Compounds 44 and 45 both exhibit high bioavailability in mice (79\% and 100\%, respectively) and are efficacious in FGFR-dependent tumor xenograft models but show no efficacy in FGFR-independent models.

\subsection{Quinoxaline- and Naphthyridine-Based Inhibitors of FGFR}

Scientists at Astex Therapeutics, in conjunction with scientists at Janssen Pharmaceutica, utilized fragment screening approaches to design novel, highly potent compounds, which were subsequently screened in vivo using a BaF3FGFR3 xenograft model. This in vivo screening approach resulted in the identification of the pyrazolyl quinoxaline compound JNJ-42756493 (46) [28], which is a potent inhibitor of all 4 FGFR isoforms in biochemical assays (FGFR1, 2, and $4 \mathrm{IC}_{50}$ 's all $<0.001 \mu \mathrm{M}$, FGFR3 $\mathrm{IC}_{50}=0.001 \mu \mathrm{M}$ ) with reduced activity against PDGFR $\beta$ and VEGFR2 ( $\mathrm{IC}_{50}$ 's $=0.0036 \mu \mathrm{M}$ and $0.0059 \mu \mathrm{M}$, respectively) and good selectivity when tested against a commercial panel of 450 different kinases. JNJ-42756493 (46) has potent inhibitory activity in a range of cell models harboring activating FGFR alterations, including Kato III, SNU-16, RT-112, and KMS-11 models ( $\mathrm{IC}_{50}$ 's $=0.06 \mathrm{nM}, 0.37 \mathrm{nM}, 1.1 \mathrm{nM}$, and $0.0276 \mu \mathrm{M}$, respectively) and is active in a range of standard and patient-derived xenograft models. Compound 46 induced prolonged target inhibition in in vitro washout experiments, and it has been 
postulated that the basic nature of the compound results in the retention of the compound in the more acidic environment of the cellular lysosomes. This effect may also result in the cellular accumulation of the compound and might account for the differential tissue distribution observed following oral administration to rats. Although there has currently been no publication outlining the medicinal chemistry optimization of 46, a crystal structure of the compound bound to FGFR1 shows the 3,5-dimethoxyphenyl moiety to bind in the selectivity pocket, and the nitrogen in the 4-position of the quinoxaline ring makes an interaction with the hinge region of the kinase. The pyrazolyl moiety in the 2-position of the quinoxaline ring appears to head out to a solvent-exposed region, and the alkyl amine chain makes an interaction with an aspartic acid residue in the selectivity pit region of the molecule. Compound 46 has been investigated in a phase I clinical trial in patients with advanced solid tumors where it is reported to have been safe, with manageable side effects, at dose levels that elicit antitumor activity (Fig. 24).

Later disclosures from the group highlight the discovery of potent inhibitors of FGFR based on similar compounds with a pyrazolyl naphthyridine scaffold, such as 47 [29, 30]. In contrast to $\mathbf{4 6 , 4 7}$ does not appear to be retained in the lysosomes, and there is no evidence of cellular accumulation. Compound $\mathbf{4 7}$ is reported to show a more even distribution of compound between plasma and lung tissue when compared to 46. Patent literature from this group also highlights the potential to cyclize the aminoalkyl chain onto the 3,5-dimethoxyphenyl moiety to give compounds such as 48, although potency against FGFR appears reduced [31].

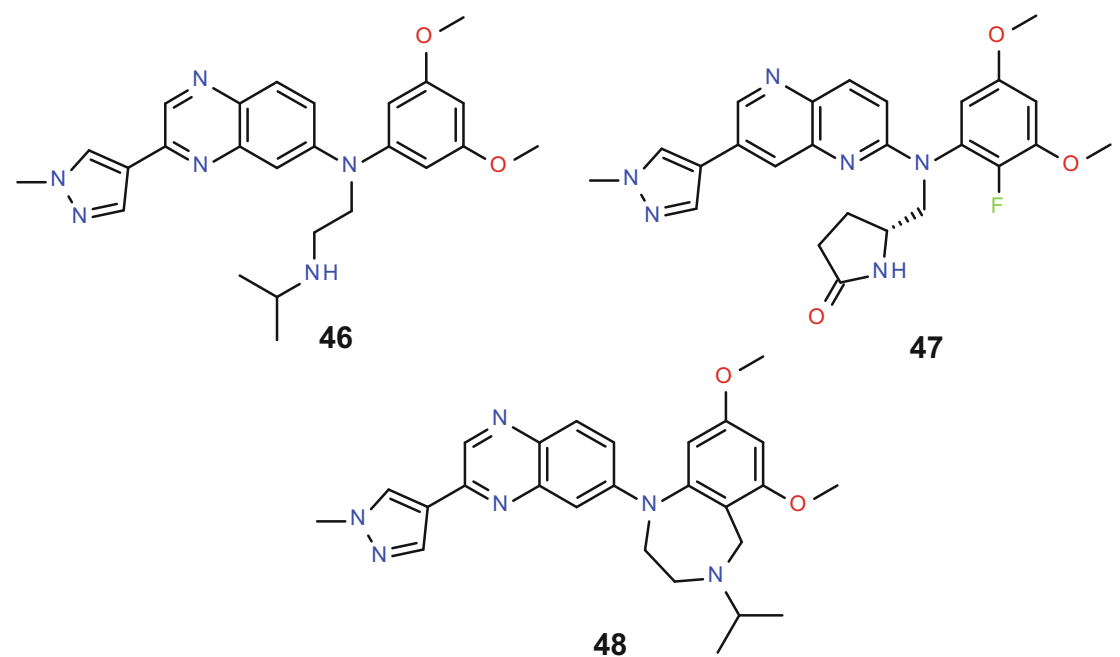

Fig. 24 Structure of quinoxaline and naphthyridine FGFR inhibitors 


\subsection{Aminopyrazolyl Inhibitors of FGFR}

The development of selective FGFR1-3 inhibitors based on a novel aminopyrazolyl scaffold has been described by scientists at Debiopharm International in conjunction with scientists at Chugai $[32,33]$. A high-throughput screening campaign resulted in the identification of 49, a moderately potent inhibitor of FGFR with similar potency against closely related kinases such as VEGFR2 and Src. A crystal structure of 49 bound into FGFR1 highlighted an interaction between both the carbonyl and the amino substituent with the hinge region of the kinase. The structure also highlighted the potential to target additional $\pi-\pi$ interactions between the inhibitor and Tyr566 and also the potential to access the back pocket to improve FGFR selectivity. Replacement of the methylphenyl ring with an azaindole group resulted in the discovery of $\mathbf{5 0}$, which shows a significant increase in kinase activity although a similar selectivity profile. Interestingly, these compounds appear to inhibit FGFR1-3 to a greater extent than FGFR4, which has also been observed with previously reported FGFR inhibitors. In addition to additional $\pi-\pi$ interactions with Tyr566, this azaindole moiety also participates in an additional hydrogen bond interaction with the kinase hinge. While seeking improvements in kinase selectivity, the authors also appreciated the need to improve the solubility $(20 \mu \mathrm{g} / \mathrm{mL}$ in simulated intestinal fluid) and metabolic stability $\left(\mathrm{Cl}_{\text {int }}=15 \mu \mathrm{L} / \mathrm{min} / \mathrm{mg}\right.$ in human microsome incubations) of $\mathbf{5 0}$ in order to find a compound suitable for clinical development. A variety of basic functionality is reported to be tolerated when attached to the 5- or 6-positions of the azaindole ring, and while improvements were seen in both kinase activity and solubility, these improvements were offset by increased turnover in human microsome incubations. The importance of the phenolic functionality was also highlighted with its removal resulting in a significant reduction in potency resulting in the authors examining known phenol isosteres such as benzimidazole. Replacement of the phenol ring with a benzimidazole ring was tolerated, and, in particular, replacement with a methylbenzimidazole moiety gave improved FGFR activity and a significant improvement in selectivity, for example, 51. The authors suggest that the high levels of selectivity observed for $\mathbf{5 1}$ are derived from an interaction with Met535 which is unique among the previously reported FGFR inhibitors. In addition to selectivity over closely related kinases, compound $\mathbf{5 1}$ displays high levels of selectivity when assessed in a commercially available panel of 442 kinases and was subsequently given the corporate identifier of CH5183284 (also referred to as Debio 1347). The solubility of CH518284 (51) in FaSSIF remains modest $(19 \mu \mathrm{g} / \mathrm{mL})$, but the compound shows significantly improved stability in human microsomal incubations $\left(\mathrm{Cl}_{\text {int }}=0.16 \mu \mathrm{L} / \mathrm{min} / \mathrm{mg}\right)$ and shows good oral exposure in both rat and monkey following oral administration. Further improvements in both potency and solubility were obtained following the addition of a weakly basic morpholine unit to give compound 52; however, despite the stability of the compound in human microsomal incubations $\left(\mathrm{Cl}_{\mathrm{int}}=0.87 \mu \mathrm{L} / \mathrm{min} / \mathrm{mg}\right)$, the compound shows significantly lower exposure in rat and monkey studies (Fig. 25). 
<smiles>Cc1cccc(C(=O)c2cnn(-c3cc(O)ccc3Cl)c2N)c1</smiles>

49<smiles>Nc1c(C(=O)c2cc3ccccc3[nH]2)cnn1-c1cc(O)ccc1Cl</smiles>

50<smiles>Cc1nc2cc(-n3ncc(C(=O)c4cc5ccc(CN6CCOCC6)cc5[nH]4)c3N)ccc2[nH]1</smiles>

\begin{tabular}{|c|c|c|c|c|}
\hline Compound & $\mathbf{4 9}$ & $\mathbf{5 0}$ & $\mathbf{5 1}$ & $\mathbf{5 2}$ \\
\hline FGFR1 IC $_{50}(\mu \mathrm{M})$ & 1.9 & 0.13 & 0.0093 & 0.0015 \\
\hline FGFR2 IC $50(\mu \mathrm{M})$ & 0.94 & 0.03 & 0.0076 & 0.0036 \\
\hline FGFR3 IC $50(\mu \mathrm{M})$ & 7.4 & 0.025 & 0.022 & 0.0035 \\
\hline FGFR4 IC $50(\mu \mathrm{M})$ & 4.1 & 0.20 & 0.29 & 0.013 \\
\hline VEGFR2 IC $_{50}(\mu \mathrm{M})$ & 2.9 & 0.028 & 2.1 & 0.12 \\
\hline
\end{tabular}

Fig. 25 Structure of aminopyrazolyl FGFR inhibitors

Western blot analysis shows that CH518284 (51) can potently inhibit the phosphorylation of FGFR 1-3 in cells but that it has significantly reduced activity against FGFR4, VEGFR2, and PDGFR $\beta$. Compound 51 shows strong antiproliferative activity against a range of cancer cell lines harboring genetic alterations in FGFR and activity in a range of xenograft models which also harbor genetic alterations in FGFR. At doses similar to those shown to be efficacious in certain xenograft models, 51 shows little impact on the in vivo diastolic blood pressure in rats and has no effect in an in vitro VEGF-induced tube-forming assay at concentrations of $1 \mu \mathrm{M}$. The authors also report that $\mathbf{5 1}$ shows activity in both in vitro and in vivo models of a relevant FGFR2 gatekeeper mutant (V564F), and they speculate that this may differentiate the compound from other FGFR inhibitors reported. At the time of writing, CH518284 (51) was undergoing phase I clinical evaluation in selected patients harboring genetic alterations in FGFR. 


\subsection{Selected Other FGFR Kinase Inhibitors}

A wide variety of additional ATP-competitive inhibitors of FGFR have been reported but with only limited details on the structure and medicinal chemistry discovery disclosed. A brief description of the available data for a selection of compounds which have recently entered clinical investigation is reported below.

Scientists at Bayer have recently disclosed BAY 1163877, a potent and selective inhibitor of FGFR1-3 kinase activity with oral exposure [34, 35]. BAY1163877 is reported to potently inhibit the activity of FGFR1-3 in biochemical assays ( $\mathrm{IC}_{50}$ 's $=0.011 \mu \mathrm{M},<0.001 \mu \mathrm{M}$, and $0.0185 \mu \mathrm{M}$, respectively) while showing good levels of selectivity when tested against a panel of 222 kinases. BAY 1163877 is reported to inhibit the proliferation of various cancer cell lines in vitro and to show in vivo efficacy in a range of xenograft models presenting at least one FGFR alteration. In the PDX HN9897 model, shown to over express FGFR3, efficacy was observed at doses of 35 and $50 \mathrm{mg} / \mathrm{kg}$ bid. BAY 1163877 is reported to be in phase 1 clinical trials, and while no structure has yet been disclosed for this molecule, a number of patents have recently been published disclosing a series of pyrrolo[2,1-f] $[1,2,4]$ triazin-4-amine-based inhibitors of FGFR, exemplified by 53, 54, and $\mathbf{5 5}$ [36-38]. It is therefore possible that BAY 1163877 may be contained within these publications. Comparison of these published structures with those of known FGFR inhibitors would suggest that the triazine-amine portion of the molecule is likely to be involved in the key interaction with the kinase hinge, while the substitution pattern on the benzothiophene moiety is similar to that observed with many substituents often located in the back pocket (Fig. 26).

The discovery of the amidopyridyl compound E7090 (56) has recently been disclosed by scientists from the laboratories of Eisai [39]. Compound 56 is a potent and selective inhibitor of FGFR1-3 currently in early clinical studies. It is active against FGFR1-3 in biochemical assays $\left(\mathrm{IC}_{50}\right.$ 's $=0.0007 \mu \mathrm{M}, 0.0005 \mu \mathrm{M}$, and $0.0012 \mu \mathrm{M}$, respectively) but shows reduced activity against both FGFR4 and VEGFR2 $\left(\mathrm{IC}_{50}\right.$ 's $=0.12 \mu \mathrm{M}$ and $0.016 \mu \mathrm{M}$, respectively). While the medicinal
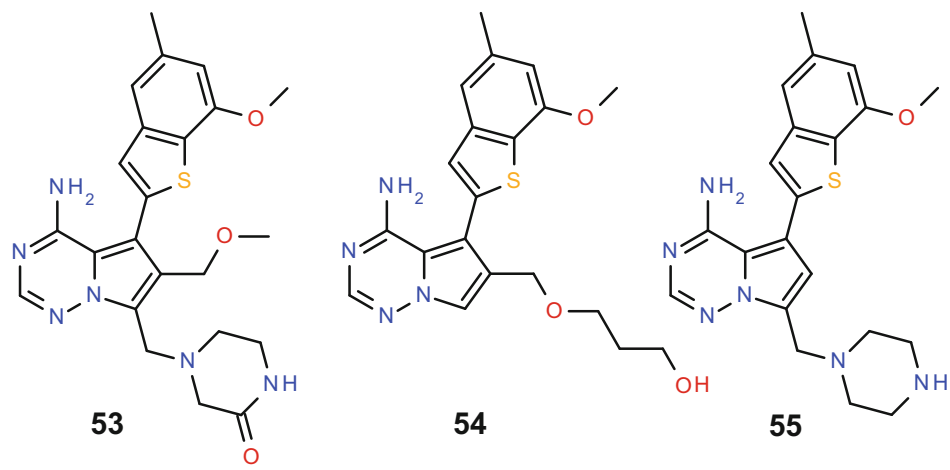

Fig. 26 Examples of pyrrolo[2,1-f] [1,2,4]triazin-4-amine-based FGFR inhibitors described in WO 2013124316, WO2013087578, and WO 2013087647 
chemistry which resulted in the discovery of $\mathbf{5 6}$ has yet to be disclosed, comparison with other kinase inhibitors suggests that the pyridyl amide motif is likely to bind to the kinase hinge, while the hydroxyethyl piperidine moiety is likely to be positioned in the solvent channel. Interestingly, $\mathbf{5 6}$ is one of the few selective FGFR inhibitors reported which does not utilize a 3,5-disubstituted aryl motif to bind into the back pocket. Compound 56 appears to be broadly selective for FGFR1-3 when tested in a panel of 93 kinases. Compound 56 inhibits the proliferation of various cancer cell lines harboring alterations to FGFR, for example, SNU-16 and KMS-11 $\left(\mathrm{IC}_{50}\right.$ 's $=0.003 \mu \mathrm{M}$ and $0.008 \mu \mathrm{M}$, respectively), while having lower activity in VEGFR-stimulated HUVEC cells $\left(\mathrm{IC}_{50}=0.19 \mu \mathrm{M}\right)$. E7090 (56) is active in a range of xenograft models, including SNU-16 where the activity is associated with inhibition of phosphorylation of FGFR2 and elevation of plasma FGF23 levels, and has shown improved survival times in a 4T1 lung metastasis model in mice (Fig. 27).

Scientists at Incyte Corporation Inc. have recently reported the discovery of a selective inhibitor of FGFR1-3. The inhibitor, INCB54828, is a potent inhibitor of FGFR1-3 in biochemical assays $\left(\mathrm{IC}_{50}\right.$ 's $=0.0004 \mu \mathrm{M}, 0.0005 \mu \mathrm{M}$, and $0.001 \mu \mathrm{M}$, respectively) but with reduced activity against both FGFR4 and VEGFR2 ( $\mathrm{IC}_{50}$ 's $=0.030 \mu \mathrm{M}$ and $0.071 \mu \mathrm{M}$, respectively) [40]. INCB54828 was shown to be a selective inhibitor of FGFR when tested against a panel of 161 kinases and inhibited the phosphorylation of FGFR in KATO-III cells with an $\mathrm{IC}_{50}$ of $0.0003 \mu \mathrm{M}$. INCB54828 selectively inhibited the growth of cancer cell lines in which FGFR was activated, such as KATO-III and RT-112 $\left(\mathrm{GI}_{50}\right.$ 's $=0.003 \mu \mathrm{M}$ and $0.007 \mu \mathrm{M}$, respectively), and has shown efficacy in KATO-III and RT-112 xenograft models at doses of 0.3 and $1 \mathrm{mg} / \mathrm{kg}$ qd. INCB54828 is currently undergoing a clinical phase I study. While the unique structure of INCB54828 has yet to be disclosed, a generalized scaffold has been presented (57). Recent patent publications from Incyte have disclosed a number of closely related FGFR inhibitors (exemplified by 58) [41, 42]. Comparison of these structures with those of known FGFR inhibitors suggests that the azaindole/azabenzimidazole core of INCB54828 is likely to be involved in a bidentate interaction with the kinase hinge, while the

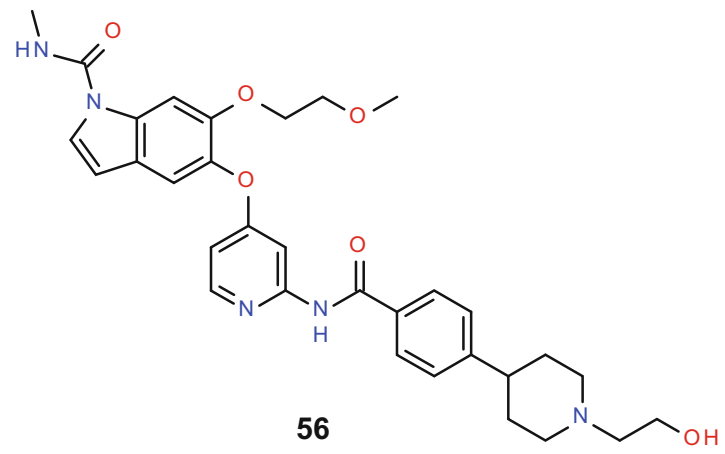

Fig. 27 Structure of E7090 


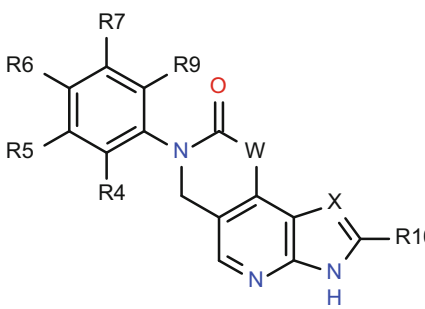

57<smiles>COc1cc(OC)c(F)c(N2Cc3cnc(N)c(C)c3N(C)C2=O)c1F</smiles>

58

Fig. 28 Generalized structure of INCB54828 (57) and representative compound from WO $2014172644(\mathbf{5 8})$

3,5-dimethoxy substituents exemplified in the patents suggest that this pendant phenyl ring is likely to occupy the back pocket. The $\mathrm{R}^{10}$ substituent is likely to be positioned such that it could access the solvent channel and may therefore provide an opportunity to modulate the physicochemical and pharmacokinetic properties of the molecule in addition to the binding affinity (Fig. 28).

\section{Irreversible Inhibitors of FGFR}

A different approach to the identification of selective FGFR inhibitors has been described by Gray et al. from the Dana-Farber Cancer Institute, Harvard Medical School, working in collaboration with researchers at the Scripps Research Institute and the Massachusetts General Hospital Cancer Center. The approach described involved the design of compounds to inhibit FGFR in an irreversible manner [43]. Irreversible inhibitors developed to date usually possess electrophilic functionality, often $\alpha, \beta$-unsaturated carbonyls such as acrylamides, to react with nucleophilic thiol groups on cysteine residues in a binding site. Irreversible inhibitors can exploit both the inherent selectivity resulting from non-covalent binding interactions, in addition to the requirement for a protein to possess a suitably located cysteine residue, to achieve high levels of selectivity. The authors identified a suitable cysteine present at the rim of the $P$-loop in FGFR1 (Cys486), which is conserved across all four FGFR isoforms and thus looked to develop irreversible inhibitors targeting this residue. In addition to increased selectivity, it was also appreciated that the kinetics of irreversible binding may, in part, overcome issues with suboptimal pharmacokinetics, such as rapid clearance, which may have limited the efficacy of other FGFR inhibitors described.

Careful inspection of the published crystal structure of PD173074 (7) bound to FGFR 1 identified the Cys486 residue to be located was approximately $10 \AA$ from the pyridine nitrogen of 7 . The authors selected a related pyrimido[4,5]pyrimidine scaffold and introduced a phenyl ring bearing a meta-acrylamide group to the pyridine nitrogen to give compound 59. Compound 59 binds to FGFR1 but shows 
a 300-fold reduction in antiproliferative activity compared to 7 in assays using BaF3 cells transfected with FGFR1. The authors postulate that electrophilic functionality in $\mathbf{5 9}$ was not optimally positioned to form a covalent bond with the cysteine and instigated the investigation of alternate linking groups. The inclusion of a methylene group between the nitrogen and the phenyl ring resulted in compound 60 which shows improved potency. Computational modeling suggests that the $\beta$-carbon of the acrylamide unit in $\mathbf{6 0}$ is positioned $2.9 \AA$ from Cys486, a distance considered suitable for covalent bond formation. The authors were able to utilize previously disclosed SAR studies from other scaffold to rapidly design FIIN-1 (61), which contains a 2,6-dichloro-3,5-dimethoxyphenyl ring anticipated to better fill the hydrophobic back pocket of the binding site. FIIN-1 (61) showed potent antiproliferative activity in BaF3 cells transfected with either FGFR1 or FGFR3. The reduced compound, FRIN-1 (62), which is unable to form a covalent bond with Cys486, was observed to be significantly less potent in these assays thus suggesting a functional importance for the acrylamide unit (Fig. 29).<smiles>C=CC(=O)Nc1cccc(N2C(=O)N(c3cc(OC)cc(OC)c3)Cc3cnc(NCCCCN(CC)CC)nc32)c1</smiles><smiles>C=CC(=O)Nc1cccc(CN2C(=O)N(c3cc(OC)cc(OC)c3)Cc3cnc(NCCCCN(CC)CC)nc32)c1</smiles><smiles>C=CC(=O)Nc1cccc(CN2C(=O)N(c3c(Cl)c(OC)cc(OC)c3Cl)Cc3cnc(NCCCCN(CC)CC)nc32)c1</smiles>

\begin{tabular}{|c|c|c|c|c|}
\hline Compound & $\mathbf{5 9}$ & $\mathbf{6 0}$ & $\mathbf{6 1}$ & $\mathbf{6 2}$ \\
\hline BaF3-FGFR1 IC $_{50}(\mu \mathrm{M})$ & 1.5 & 0.40 & 0.014 & 0.34 \\
\hline BaF3-FGFR3 IC $_{50}(\mu \mathrm{M})$ & - & - & 0.010 & 1.04 \\
\hline
\end{tabular}

Fig. 29 SAR of irreversible inhibitors of FGFR 
The selectivity of FIIN-1 (61) was investigated against a panel of 402 different kinase-binding assays using the Ambit KinomeScan technology at a concentration of $10 \mu \mathrm{M}$, and dissociation constants $\left(K_{D}\right.$ 's) were determined for those kinases which were displaced to greater than $90 \%$ of the DMSO control. Compound 61 was seen to bind strongly to FGFR $1-3\left(K_{D}\right.$ 's $=0.0028 \mu \mathrm{M}, 0.0069 \mu \mathrm{M}$ and $0.0054 \mu \mathrm{M}$, respectively) but was significantly less potent against FGFR4 $\left(K_{D}=0.12 \mu \mathrm{M}\right)$. Only two other kinases were found to have $K_{D}$ values below $0.1 \mu \mathrm{M}$; these were Blk $(0.065 \mu \mathrm{M})$ and Flt1 $(0.032 \mu \mathrm{M})$. FIIN-1 (61) is reported to exhibit good selectivity over kinases such as c-Src, TNK1, and YES which have cysteine residues located in the same region of the binding site. Together these results indicate that $\mathbf{6 1}$ is a potent and selective inhibitor of FGFR1-3. Interestingly, similar biochemical potency was observed for FRIN-1 (62) against FGFR1-4 $\left(K_{D}=0.0031 \mu \mathrm{M}\right.$, $0.0056 \mu \mathrm{M}, 0.0054 \mu \mathrm{M}$, and $0.28 \mu \mathrm{M}$, respectively) suggesting that the majority of the binding energy arises from non-covalent interactions within the binding site. Washout experiments in MCF10A cells demonstrate that $\mathbf{6 1}$ gives sustained inhibition of phosphorylation of both FGFR1 and ERK1/2 following washout of the drug, consistent with the proposed mechanism of irreversible inhibition. In contrast, similar experiments with either $\mathbf{7}$ or $\mathbf{6 2}$ demonstrate that inhibitory activity is almost completely eradicated by the washout procedure suggesting these agents act in a reversible manner. Further evidence supporting the covalent binding of 61 was developed by synthesizing biotinylated versions of both FIIN-1 (61) and FRIN-1 (62). These biotinylated analogues maintained cellular potency and FIIN1-biotin, but not FRIN-1-biotin was found to covalently label FGFR1. Furthermore, FIIN-1-biotin was shown to covalently label wild-type FGFR1 but not an FGFR1C486S construct supporting the initial hypothesis that Cys486 is the site of covalent modification.

\section{Isoform-Selective FGFR Inhibitors}

Although significant progress has been made in identifying FGFR inhibitors devoid of broad spectrum kinase activity and with promising selectivity over closely related growth factor receptor tyrosine kinases, such as VEGFR2, identifying compounds which display selectivity between the individual isoforms of FGFR remains a challenge. Given the high degree of homology between the ATP-binding sites of the four FGFR isoforms, it is perhaps not surprising that the inhibitors discussed so far have shown a pan-FGFR profile; although it is worth noting that a number of the more selective pan-FGFR inhibitors developed to date actually show a preference for FGFR1-3 over FGFR4. It has been widely postulated that the ability to selectivity inhibit a single isoform of FGFR may result in compounds with improved therapeutic margins. In particular, there is evidence that inhibition of FGFR1 is associated with mineralization in preclinical models and may cause doselimiting effects in the clinic [44]. 


\subsection{FGFR4-Selective Inhibitors}

The preferential inhibition of FGFR1-3, displayed by many compounds including BGJ-398 (31), AZD4547 (41), and FIIN-1 (61), has been appreciated by a number of groups who suggest such compounds may be unsuited to treat FGFR4-mediated disease as a result of the concomitant FGFR1-3-mediated pharmacology. FGFR4 is overexpressed in several cancers including colon, liver, breast, and prostate, although the role of FGFR4 in cancer is yet to be fully elucidated [45]. FGFR4 has also been implicated in rhabdomyosarcoma (RMS) in which mutations have been identified in 7-8\% of RMS tumors, and high expression of FGFR4 is associated with poor prognosis [46]. More recently evidence has emerged demonstrating a key role for FGFR4 in hepatocellular cancer (HCC). FGF19 has unique specificity for FGFR4, and hence the FGFR4 receptor is considered the principal controller of FGF19 signaling. For FGF19 to bind to FGFR4, an additional transmembrane protein $\beta$-Klotho is required. High expression levels of both FGFR4 and $\beta$-Klotho are seen in the liver thereby strengthening the evidence that the FGFR4-FGF19 signaling axis is a key driver in HCC. Recent results have shown that in preclinical models of HCC, an FGFR4-neutralizing antibody inhibits tumor formation and development in FGF19 transgenic mice, thus suggesting the potential for FGFR4 inhibition to have therapeutic utility [47].

Pike et al. have described the work undertaken within the laboratories of AstraZeneca to identify selective small molecule inhibitors of FGFR4 [48]. When screening approaches failed to identify FGFR4-selective chemical equity within the existing AstraZeneca compound collection, the researchers looked to adopt a strategy of structure-guided drug design. Detailed inspection of the ATP-binding sites in the different FGFR isoforms highlighted a number of subtle differences in the residues lining the solvent channel of FGFR4 compared with FGFR1-3. A more significant difference was observed in the hinge region of the kinase where a bulky tyrosine residue in FGFR1-3 (Tyr563 in FGFR1) is replaced with a smaller cysteine residue in FGFR4 (Cys552 in FGFR4). The authors hypothesized that compounds that protrude into these regions may display differential binding to the individual isoforms thereby delivering compounds with selectivity for FGFR4. Interestingly, only five other kinases in the kinome contain a cysteine in this position suggesting that an FGFR4-selective inhibitor may also show excellent selectivity against a broad spectrum of kinases. For the optimization of such compounds, the authors selected an imidazopyridine scaffold which was known to bind to FGFR from in-house kinase selectivity screening. A crystal structure of compound $\mathbf{6 3}$ bound into FGFR1 highlights a key interaction between the imidazopyridine $\mathrm{N} 1$ and Ala564 in the kinase hinge region. In addition, hydrogen-bonding interactions are seen between Asp641 and both the terminal amide group and aminopyrazine NH. The aminoamide aryl substituent is positioned in a hydrophobic pocket under the $P$-loop, and the orientation is controlled by the chirality of the terminal substituents. Importantly, while compound $\mathbf{6 3}$ shows no inherent selectivity for FGFR4, in fact it shows a preferential inhibition of FGFR1 
in biochemical assays and preferential inhibition of phosphorylation of FGFR in Cos-1 cells transfected with either FGFR1 or FGFR4; the imidazopyridine scaffold was appreciated to contain suitable vectors for substitution to target the identified differences in both the solvent channel and the hinge region of the protein.

While substitution on the 6-position of the imidazopyridine ring could indeed access the solvent channel and result in increased kinase potency, no evidence of FGFR4 selectivity was observed (data not shown). Substitution at the 7-position of the imidazopyridine ring was envisaged to position substituents in close proximity to the kinase hinge with the potential to exploit the presence of the less bulky cysteine residue in FGFR4. However, despite the potential extra space in the hinge region of FGFR4, it was appreciated that additional steric bulk in this region might adversely affect the interaction between the imidazopyridine N1 and the kinase hinge thus resulting in an erosion of kinase activity (Fig. 30).

The introduction of small substituents such as fluoro, 64, or cyano, 65, was observed to reduce potency against FGFR4, albeit the impact was moderate. Interestingly, FGFR1 potency was eroded to a much greater extent, supporting the hypothesis that FGFR1 is less able to accommodate steric bulk in this region. As

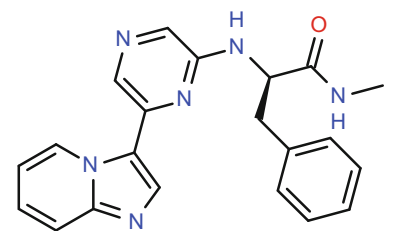

63

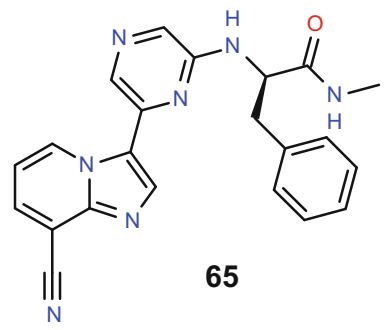

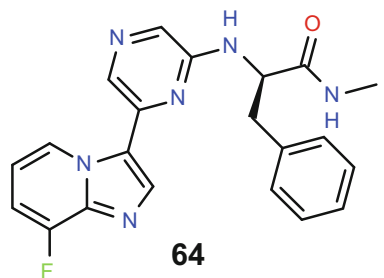

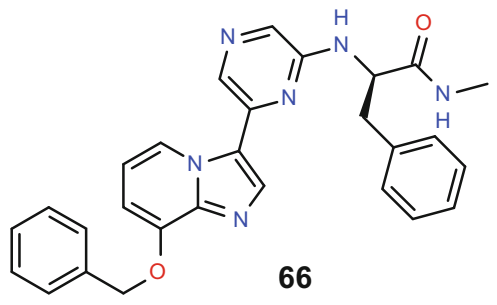

\begin{tabular}{|c|c|c|c|c|}
\hline Compound & $\mathbf{6 3}$ & $\mathbf{6 4}$ & $\mathbf{6 5}$ & $\mathbf{6 6}$ \\
\hline FGFR1 IC $_{50}(\mu \mathrm{M})$ & 0.025 & 0.059 & 1.33 & 3.88 \\
\hline FGFR4 IC $50(\mu \mathrm{M})$ & 0.048 & 0.162 & 0.24 & 0.050 \\
\hline Cos-1 pFGFR1 IC $50(\mu \mathrm{M})$ & 0.028 & 0.361 & 5.76 & $>4.7$ \\
\hline Cos-1 pFGFR4 IC $50(\mu \mathrm{M})$ & 0.124 & 0.268 & 0.496 & 0.064 \\
\hline
\end{tabular}

Fig. 30 SAR of 7-substituted imidazopyridines 
a result, low levels of FGFR4 selectivity were apparent. The incorporation of the large 7-benzyloxy substituent resulted in almost complete eradication of FGFR1 activity, while FGFR4 potency was maintained, 66. Compound 66, therefore, represents a potent and selective inhibitor of FGFR4 and validates the original hypothesis. The authors report that computational simulations suggest that the incorporation of a large substituent in the 7-position of the imidazopyridine core results in a reorganization the hinge residue side chains. The energy penalty for this is calculated to be lower in the case of FGFR4 due to the presence of the smaller cysteine residue. However, the authors also note that the high lipophilicity and low aqueous solubility of compounds such as $\mathbf{6 6}$ will limit the ability to characterize compounds in vivo. Reducing the bulk of the aminoamide substituent, 67, does result in improved physicochemical properties but is accompanied by a reduction in FGFR4 activity. A wide range of substituents was investigated in the 7-position of the imidazopyridine core resulting in the identification of AZ9709 (68). Compound 68 is a potent inhibitor of FGFR4 with excellent levels of selectivity over FGFR1 in both biochemical and cell assays. The broad kinase selectivity of $\mathbf{6 8}$ was assessed against a commercially available panel of 76 different kinases binding assays. None of the kinases tested were inhibited by greater than $50 \%$ when treated with $\mathbf{6 8}$ at $1 \mu \mathrm{M}$ suggesting that the compound has excellent general kinase selectivity. Compound 68 showed potent antiproliferative effects against Huh-7 cells which are known to overexpress FGF19 and possess functional FGFR4 $\left(\mathrm{GI}_{50}=0.116 \mu \mathrm{M}\right)$. The pharmacokinetic profile of $\mathbf{6 8}$ in mouse was considered suitable for in vivo assessment of target engagement, and it, 68, showed a dose-dependent inhibition of phosphorylation FRS2 which was maintained for up to $8 \mathrm{~h}$ following a single dose of either 150 or $300 \mathrm{mg} / \mathrm{kg}$ in mice bearing Huh-7 tumors. This result supports the assertion that 68 can effectively inhibit FGFR4 in vivo. A crystal structure of $\mathbf{6 8}$ bound to both FGFR1 and a construct of FGFR1 mutated to resemble the binding site of FGFR4 (FGFR1Y563C) confirms that the 7-triazole substituent is positioned in contact with the kinase hinge as predicted and that Tyr563 present in the FGFR1 is required to move $2.8 \AA$ compared to where it is located in the majority of other FGFR1-inhibitor complexes with available structural information. Such a reorganization is not apparent in the structure of $\mathbf{6 8}$ bound to the FGFRY563C construct. The reorganization of the tyrosine residue is consistent with the initial hypothesis explaining the observed FGFR4 selectivity (Fig. 31).

The presence of an FGFR4-specific cysteine residue in the ATP-binding site also allows the possibility of gaining FGFR4 selectivity through the use of an irreversible inhibitor. Pike et al. also describe the synthesis of compound 69 which contains electrophilic functionality directed toward the kinase hinge. Compound 69 shows selectivity for FGFR4 over FGFR1, and the irreversible nature of the inhibition is supported by the observation of covalent adducts between FGFR4 and $\mathbf{6 9}$ upon incubation of compound with protein.

The potential to achieve selectivity for FGFR4 over FGFR1-3 through the covalent modification of Cys552 has also been appreciated by Hagel et al. who have reported the discovery of BLU9931 (70) from the laboratories of Blueprint Medicines [49]. The authors drew inspiration from the structure of the known 

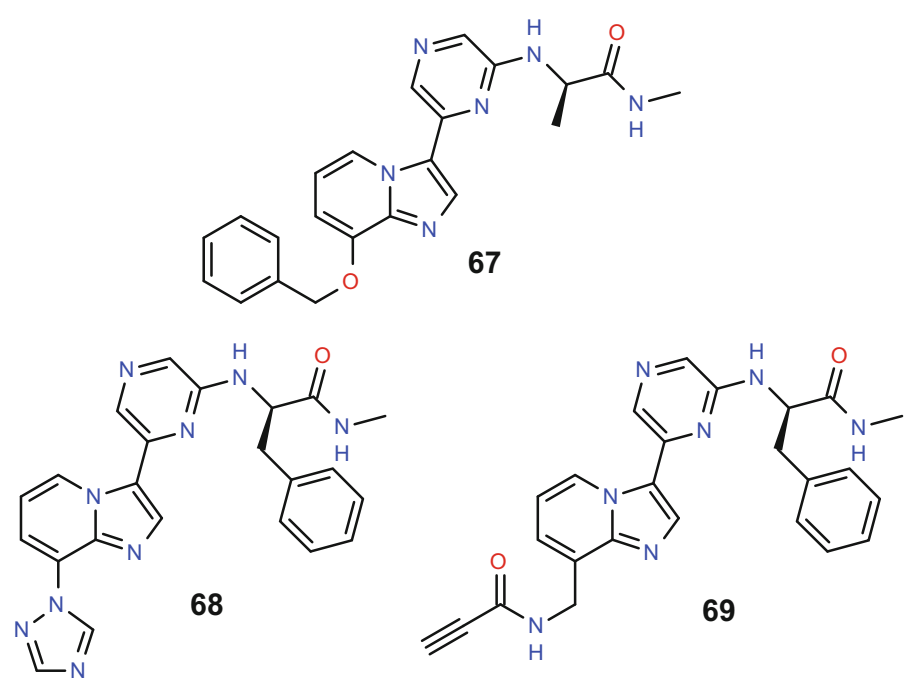

\begin{tabular}{|c|c|c|c|}
\hline Compound & $\mathbf{6 7}$ & $\mathbf{6 8}$ & $\mathbf{6 9}$ \\
\hline FGFR1 IC $_{50}(\mu \mathrm{M})$ & 28.0 & 5.17 & 0.688 \\
\hline FGFR4 IC $_{50}(\mu \mathrm{M})$ & 1.33 & 0.050 & 0.009 \\
\hline Cos-1 pFGFR1 IC $50(\mu \mathrm{M})$ & $>10$ & $>10$ & $>8.6$ \\
\hline Cos-1 pFGFR4 IC $50(\mu \mathrm{M})$ & 2.67 & 0.053 & 0.070 \\
\hline
\end{tabular}

Fig. 31 SAR of FGFR4 selective imidazopyridines

inhibitor PD173074 (7) bound into FGFR1 and used this knowledge to design a series of anilinoquinazoline compounds targeting Cys552. Although detailed SAR for this scaffold has yet to be disclosed, it is clear that a 2,6-dichloro-3,5dimethoxyphenyl substituent was introduced to the C6 position of the quinazoline core in an attempt to efficiently occupy the hydrophobic back pocket. Exploration of the 2-anilino moiety revealed that covalent modification of Cys552 was possible when an electrophilic acrylamide motif was positioned adjacent to the aniline nitrogen. However, the level of selectivity achieved for FGFR4 with initial compounds was disappointing suggesting the positioning of the electrophile was suboptimal. The incorporation of a methyl group in the remaining ortho-position of the anilino ring was anticipated to increase the rotation of the ring out of the plane of the quinazoline core thereby achieving a more optimal geometry for the formation of the covalent bond and resulted in the discovery of $\mathbf{7 0}$. The rotation of this anilino ring is also believed to induce a steric clash with the more bulky tyrosine residue in FGFR1-3 thereby increasing FGFR4 selectivity. BLU9931 
(70) shows good potency and selectivity for FGFR4 in biochemical assays (FGFR1-4 IC 50 's $0.591 \mu \mathrm{M}, 0.493 \mu \mathrm{M}, 0.150 \mu \mathrm{M}$, and $0.003 \mu \mathrm{M}$, respectively). The authors report that reduction of BLU9931 (70) results in an analogue possessing significantly lower activity against FGFR4 $\left(\mathrm{IC}_{50}=0.938 \mu \mathrm{M}\right)$ thus supporting the importance of the covalent bond formation on the inhibitory activity. Further evidence of the irreversible inhibition mechanism is provided by the observation of a covalent adduct between $\mathbf{7 0}$ and recombinant FGFR4 protein following incubation. A crystal structure of $\mathbf{7 0}$ bound to FGFR4 indicates the anticipated binding mode in which the anilinoquinazoline core forms a bidentate hydrogen-bonding interaction with the hinge region, while the 2,6-dichloro-3,5dimethoxyphenyl residue occupies the hydrophobic back pocket. The aniline phenyl ring is rotated through approximately $60^{\circ}$ compared to the plane of the quinazoline ring orientating the acrylamide toward the sulfur of the Cys552 residue (Fig. 32).

Testing of BLU9931 (70) against a broad panel of 456 wild type and diseaserelevant mutant kinases at $3 \mu \mathrm{M}$ resulted in only two kinases showing inhibition of greater than $90 \%$ of DMSO control (FGFR $4=99.7 \%, \mathrm{CSF} 1 \mathrm{R}=90.1 \%$ ) thereby highlighting the exceptional kinase selectivity of the molecule. Compound $\mathbf{7 0}$ showed potent antiproliferative effects in HCC cell lines known to overexpress FGF19 and contain functional FGFR4 (such as Hep3B EC E0 $_{0}=0.07 \mu \mathrm{M}$, Huh-7 $\mathrm{EC}_{50}=0.11 \mu \mathrm{M}, \mathrm{JHH}-7 \mathrm{EC}_{50}=0.02 \mu \mathrm{M}$ ). Compound 70 displays a moderate bioavailability of $18 \%$ and a half-life of $2.3 \mathrm{~h}$ in mouse and showed tumor regression in mice bearing Hep3B tumors following administration of $100 \mathrm{mg} / \mathrm{kg}$ twice a day for 21 days. Furthermore, two of the animals from this treatment group showed no regrowth of tumor 30 days after cessation of treatment suggesting that selective inhibition of FGFR4 can give durable efficacy in FGFR4-FGF19-driven HCC tumors.

Information issued by Novartis regarding the current equity within its pipeline reports the development of a compound, FGF401, which binds to and inhibits the activity of FGFR4. They report that FGF401 is at least 1,000-fold more potent against FGFR4 than it is against other kinases, including FGFR1-3. They report that the compound inhibits the proliferation of HCC cell lines and shows blockage of both FGFR4 signaling and tumor growth in animal models of human HCC. At the time of writing, a phase I clinical trial to evaluate FGF401 in patients with HCC

Fig. 32 Structure of BLU9931

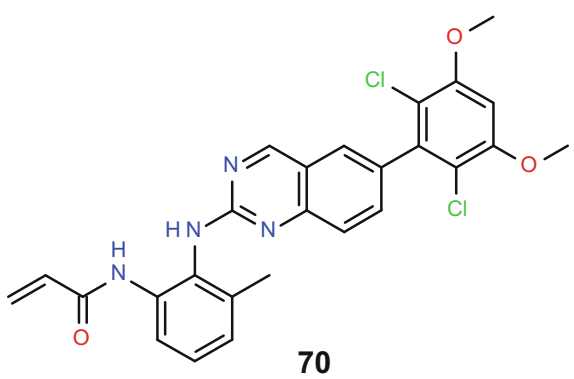


or solid malignancies characterized by positive FGFR4 and $\beta$-Klotho was recruiting, but no specific biological data or structural data concerning the compound or close analogues had been disclosed.

\subsection{FGFR3-Selective Inhibitors}

More recently Winski et al. have reported the identification of novel inhibitors developed in the laboratories of Array BioPharma, in collaboration with researchers from LOXO Oncology, Stamford, which display nanomolar inhibition of FGFR3 but relatively spare FGFR1 [50]. The authors report that these inhibitors have minimal activity against a panel of over 200 kinases. Although no structures have yet been disclosed for these inhibitors, they are reported to give high oral exposure in rodents and demonstrate tumor regression in the FGFR3-driven RT-122/84 subcutaneous xenograft models, when dosed for 14 days at either 30 or $45 \mathrm{mg} / \mathrm{kg} /$ day. The authors report only minimal hyperphosphatemia at these doses suggesting in vivo selectivity for FGFR3 over FGFR1 and supporting the hypothesis that isoform-selective FGFR inhibitors may provide treatments with improved efficacy and tolerability when compared to the pan-FGFR inhibitors currently undergoing clinical trials.

\section{Inhibitors of Inactive Forms of FGFR}

Targeting the inactive form of a kinase has long been considered an attractive concept due to the hypothesis that the inactive form would be more likely to adopt a distinct conformation, thereby presenting an opportunity to identify inhibitors of greater selectivity. The most widely reported approach to targeting an inactive form of a kinase focuses on the identification of so-called type II inhibitors. Such inhibitors characteristically induce a DFG-out conformation in which the Phe side chain of the activation loop (the $F$ of the DFG) is flipped out to leave a hydrophobic pocket which is subsequently occupied by the inhibitor. Norman et al. at AstraZeneca have reported detailed crystallographic studies into the binding of the nonselective inhibitor ponatinib ("Inhibitors of Vascular Endothelial Growth Factor Receptor") in both FGFR1 and FGFR4 [51]. These studies reveal that ponatinib acts as a type II inhibitor of FGFR and induces a DFG-out conformation. Previous to this disclosure, all reported crystal structures of FGFR-inhibitor complexes have shown the FGFR protein in the DFG-in conformation. The authors speculate that the ability to induce a DFG-out conformation of FGFR might open new avenues for the design of novel type II inhibitors of FGFR with differing selectivity profiles and the potential for different inhibition kinetics.

Researchers at ArQule have also been interested in developing kinase inhibitors to target inactive forms of the kinase, and Eathiraj et al. have described the 
Fig. 33 Structure of ARQ523, ARQ068, and ARQ069<smiles>Nc1ncc2c(n1)-c1ccccc1CC2</smiles>

71<smiles>Nc1ncc2c(n1)-c1cccc(-c3ccccc3)c1CC2</smiles><smiles>Nc1ncc2c(n1)-c1cccc(-c3ccccc3)c1CC2</smiles>

discovery of the FGFR inhibitor ARQ069 (73) [52]. The authors examined the ATP-binding sites from multiple structures of kinases in inactive forms and were able to identify a hydrophobic pocket which is not present in active kinase structures and is distinct from the pockets described with type II inhibitors. To identify scaffolds with the potential to bind to this pocket, compound databases were screened in silico against a homology model of FGFR2. Docking studies and receptor pharmacophore fitting resulted in the identification of the 5,6-dihydrobenzo[h]quinazolin-2-amine compound ARQ523 (71) which was shown to bind to FGFR2 and inhibit its autophosphorylation with an $\mathrm{IC}_{50}$ value of $18 \mu \mathrm{M}$. Optimization of this scaffold was guided by in silico models and resulted in the identification of the enantiomeric pair of ARQ068 (72) and ARQ069 (73) (Fig. 33).

ARQ069 (73) was found to inhibit the inactive (unphosphorylated) forms of both FGFR1 and FGFR2 in biochemical assays $\left(\mathrm{IC}_{50}\right.$ 's $=0.84 \mu \mathrm{M}$ and $1.23 \mu \mathrm{M}$, respectively), whereas $\mathbf{7 2}$ did not. Neither compound showed significant activity against the phosphorylated (active) forms of FGFR1 or FGFR2. The inhibition of FGFR1 and FGFR2 by $\mathbf{7 3}$ was found to be independent of ATP concentration. In KATO-III cells, which are known to overexpress FGFR2, 73 inhibited the phosphorylation of FGFR with an $\mathrm{IC}_{50}$ value of $9.7 \mu \mathrm{M}$. Consistent with the observed lack of biochemical activity, $\mathbf{7 2}$ was inactive in this assay. A crystal structure of $\mathbf{7 3}$ in the autoinhibited form of FGFR1 shows that the aminopyrimidine group forms a bidentate interaction with the hinge region, while the 5,6-dihydrobenzo[h]quinazolin-2-amine core is sandwiched in a hydrophobic cleft. The phenyl substituent of $\mathbf{7 3}$ is positioned orthogonal to the 5,6-dihydrobenzo[h]quinazolin-2-amine core occupying the main pocket and making hydrophobic interactions with the gatekeeper residue (Val561). The authors suggest that the ability to target kinases in the autoinhibited conformation may provide a new generation of kinase inhibitors that exhibit a high degree of selectivity across the kinome.

\section{$7 \quad$ Future Perspectives}

The increasing evidence for dysregulated FGF/FGFR signaling to play a key role in the development of human cancers means the appetite for efficacious and welltolerated FGFR inhibitors remains strong. The nonselective FGFR inhibitors 
represent the most advanced clinical agents and have shown activity in patients; however, the multi-kinase inhibition profile of these compounds (in particular VEGFR inhibition) does result in a toxicity profile which will limit their utility. The more recent emergence of selective FGFR inhibitors has allowed for a more targeted approach to FGFR inhibition but has also revealed a different toxicology profile, namely, hyperphosphatemia and tissue mineralization, which are thought to represent on-target class effects. While it may be possible to manage these effects in the clinic through the modification of diet or with additional drugs, it is not surprising that recent attention has turned toward making isoform-selective FGFR inhibitors. While it is too early to say with any certainty whether such compounds will show clinical utility, it is anticipated that such compounds would possess a more favorable toxicity profile. As with many targeted therapies, the most likely role for FGFR inhibitors is likely to be in combination with chemotherapy, radiotherapy, or other molecularly targeted agents. This means that to achieve a "best in class" profile for an FGFR inhibitor, the right balance between clinical effectiveness and patient toxicity will need to be attained. Given the important role FGF/FGFR signaling plays in normal human biology and the multitude of different aberrations identified in cancer cells, the successful treatment of patients will require a personalized medicine approach based on the genetic aberrations presented, to select those patients who will gain the maximum clinical benefit from FGFR inhibition. In addition, technology designed to give tissue-specific exposure of drugs may also help increase the therapeutic margin for FGFR inhibitors.

As the use of FGFR inhibitor in the clinic increases, it would seem likely that resistance mechanisms will start to emerge as has been observed following the inhibition of other RTKs, such as EGFR. Mutations in the ATP-binding site, such as gatekeeper mutations similar to those observed to cause resistance to first generation EGFR inhibitors, may decrease the effectiveness of current FGFR inhibitors therefore requiring the development of new inhibitors. Irreversible inhibition of FGFR, or the targeting of inactive forms of the protein, may provide opportunities to overcome resistance mutations. In addition to the small molecule inhibitors of FGFR discussed above, research is also underway to develop antibody approaches to target both FGF ligands and the ligand-binding domains of FGFR. Such approaches might also provide effective inhibition of single FGFR isoforms although it is currently unclear whether the long duration of action often associated with antibody therapies would be a benefit or concern in the context of FGFR inhibition.

\section{References}

1. Wesche J, Haglund K, Haugsten EM (2011) Fibroblast growth factors and their receptors in cancer. J Biochem 437:199-213

2. Hanahan D, Weinberg RA (2000) The hallmarks of cancer. Cell 100:57-70 
3. Hanahan D, Weinberg RA (2011) The hallmarks of cancer: the next generation. Cell 144: 464-674

4. Dieci MV, Arnedos M, Andre F, Soria JC (2013) Fibroblast growth factor receptor inhibitors as a cancer treatment: from a biologic rationale to a medical perspective. Cancer Discov 3(3): 264-279

5. Brooks AN, Kilgour E, Smith PD (2012) Molecular pathways: fibroblast growth factor signaling: a new therapeutic opportunity in cancer. Clin Cancer Res 18:1855-1862

6. Liang G, Chen G, Wei X, Zhao Y, Li X (2013) Small molecule inhibition of fibroblast growth factor receptors in cancer. Cytokine Growth Factor Rev 24:467-475

7. Connolly CJC, Hamby JM, Schroeder MC, Barvian M, Panek RL, Amar A, Shen C, Kraker AJ, Fry DW, Klohs WD, Doherty AM (1997) Discovery and structure-activity studies of a novel series of pyrido[2,3- $d]$ pyrimidine tyrosine kinase inhibitors. Bioorg Med Chem Lett 7(18): 2415-2420

8. Hamby JM, Connolly CJC, Schroeder MC, Winters RT, Showalter HDH, Panek RL, Major TC, Olsewski B, Ryan MJ, Dahring T, Lu GH, Keiser J, Amar A, Shen C, Kraker AJ, Slintak V, Nelson JM, Fry DW, Bradford L, Hallak H, Doherty AM (1997) Structure-activity relationships for a novel series of pyrido[2,3-d]pyrimidine tyrosine kinase inhibitors. J Med Chem 40: 2296-2303

9. Dimitroff CJ, Klohs W, Sharma A, Pera P, Driscoll D, Veith J, Steinkampf R, Schroeder M, Klutchko S, Sumlin A, Henderson B, Dougherty TJ, Bernaki RJ (1999) Anti-angiogenic activity of selected receptor tyrosine kinase inhibitors, PD166285 and PD173074: implications for combination treatment with photodynamic therapy. Investig New Drugs 17:121-135

10. Mohammadi M, Froum S, Hamby JM, Schroeder MC, Panek RL, Lu GH, Eliseenkova AV, Green D, Schlessinger J, Hubbard SR (1998) Crystal structure of an angiogenesis inhibitor bound to the FGF receptor tyrosine kinase domain. EMBO 17(20):5896-5904

11. Thompson AM, Delaney AM, Hamby JM, Schroeder MC, Spoon TA, Crean SM, Showalter HDH, Denny WA (2005) Synthesis and structure-activity relationships of soluble 7-substituted 3-(3,5-dimethoxyphenyl)-1,6-naphthyridin-2-amines and related ureas as dual inhibitors of the fibroblast growth factor receptor- 1 and vascular endothelial growth factor receptor-2 tyrosine kinases. J Med Chem 48:4628-4653

12. Klutchko SR, Hamby JM, Boschelli DH, Wu Z, Kraker AJ, Amar AM, Hartl BG, Shen C, Klohs WD, Steinkampf RW, Driscoll DL, Nelson JM, Ellliott WL, Roberts BJ, Stoner CL, Vincent PW, Dykes DJ, Panek RL, Lu GH, Major TC, Dahring TK, Hallak H, Bradford LA, Showalter HDH, Doherty AM (1998) 2-Substituted aminopyrido[2,3-d]pyrimidin-7(8H)-ones. Structure-activity relationships against selected tyrosine kinases and in vitro and in vivo anticancer activity. J Med Chem 41:3276-3292

13. Panek RL, Lu GH, Klutchko SR, Batley BL, Dahring TK, Hamby JM, Hallek H, Doherty AM, Keiser JA (1997) In vitro pharmacological characterization of PD166285, a new nanomolar potent and broadly active protein tyrosine kinase inhibitor. J Pharmacol Exp Ther 283(3): 1433-1444

14. Sun L, Tran N, Tang F, App H, Hirth P, McMahon G, Tang C (1998) Synthesis and biological evaluation of 3-substituted indolin-2-ones: a novel class of tyrosine kinase inhibitors that exhibit selectivity toward particular receptor tyrosine kinases. J Med Chem 41:2588-2603

15. Mohammadi M, McMahon G, Sun L, Tang C, Hirth P, Yeh BK, Hubbard SR, Schlessinger J (1997) Structures of the tyrosine kinase domain of fibroblast growth factor receptor in complex with inhibitors. Science 276:955-960

16. Sun L, Tran N, Liang C, Tang F, Rice A, Schreck R, Waltz K, Shawver LK, McMahon G, Tang C (1999) Design, Synthesis, and evaluations of substituted 3-[(3- or 4-carboxyethylpyrrol-2-yl) methylidenyl]indolin-2-ones as inhibitors of VEGF, FGF, and PDGF receptor tyrosine kinases. J Med Chem 42:5120-5130

17. Kammasud N, Boonyarat C, Tsunoda S, Sakurai H, Saiki I, Grierson DS, Vajragupta O (2007) Novel inhibitor for fibroblast growth factor receptor tyrosine kinase. Bioorg Med Chem Lett $17: 4812-4818$ 
18. Kammasud N, Boonyarat C, Sanphanya K, Utsintong M, Tsunoda S, Sakurai H, Saiki I, Andre I, Grierson DS, Vajragupta O (2009) 5-Substituted pyrido[2,3-d]pyrimidine, an inhibitor against three receptor tyrosine kinases. Bioorg Med Chem Lett 19:745-750

19. Renhowe PA, Pecchi S, Shafer CM, Machajewski TD, Jazan EM, Taylor C, AntioniosMcCrea W, McBride CM, Frazier K, Wiesmann M, Lapointe GR, Feucht PH, Warne RL, Heise CC, Menezes D, Aardalen K, Ye H, He M, Le V, Vora J, Jansen JM, WernetteHammond ME, Harris AL (2009) Design, structure-activity relationships and in vivo characterisation of 4-amino-3-benzimidazol-2-ylhydroquinolin-2-ones: a novel class of receptor tyrosine kinase inhibitors. J Med Chem 52:278-292

20. Lee SH, Lopes de Menezes D, Vora J, Harris A, Ye H, Nordahl L, Garrett E, Samara E, Aukerman SL, Gelb AB, Heise C (2005) In vivo target modulation and biological activity of CHIR-258, a multitargeted growth factor receptor kinase inhibitor, in colon cancer models. Clin Cancer Res 11(10):3633-3641

21. Guagnano V, Furet P, Spanka C, Bordas V, Le Douget M, Stamm C, Brueggen J, Jensen MR, Schnell C, Schmid H, Wartmann M, Berghausen J, Drueckes P, Zimmerlin A, Brussiere D, Murray J, Porta DG (2011). J Med Chem 54:7066-7083

22. Furet P, Caravatti G, Guagnano V, Lang M, Meyer T, Schoepfer J (2008) Entry into a new class of protein kinase inhibitors by pseudo ring design. Bioorg Med Chem Lett 18:897-900

23. Norman RA, Schott A-K, Andrews DA, Breed J, Foote KM, Garner AP, Ogg D, Orme JP, Pink JH, Roberts K, Rudge DA, Thomas AP, Leach AG (2012) Protein-ligand crystal structures can guide the design of selective inhibitors of the FGFR tyrosine kinase. J Med Chem 55: 5003-5012

24. Thomas A, Theoclitou M-E, Buttar D, Ruston L, Wrigley G, Dennis M, Rudge D, Coleman T, Smith R, Gavine P, Klinowska T, Mooney L, Brooks N (2012) The discovery of AZD4547: an orally bioavailable, potent and selective N-(pyrazolyl)benzamide FGFR1-3 inhibitor. Poster \#3912 103rd AACR annual meeting

25. Gavine PR, Mooney L, Thomas AP, Al-Kadhimi K, Beck S, Coleman T, Baker D, Mellor MJ, Brooks AN, Klinowska T (2012) AZD4547: an orally bioavailable, potent, and selective inhibitor of the fibroblast growth factor receptor tyrosine kinase family. Cancer Res 72:2045

26. Zhao G, Li W-Y, Chen D, Henry JR, Li H-Y, Chen Z, Zia-Ebrahimi M, Bloem L, Zhai Y, Huss K, Peng S-B, McCann DJ (2011) A novel, selective inhibitor of fibroblast growth factor receptors that shows a potent broad spectrum of antitumor activity in several tumor xenograft models. Mol Cancer Ther 10:2200-2210

27. Squires M, Ward G, Saxty G, Berdini V, Cleasby A, King P, Angibaud P, Perera T, Fazal L, Ross D, Jones CG, Madin A, Benning RK, Vickerstaffe E, O'Brien A, Frederickson M, Reader M, Hamlett C, Batey MA, Rich S, Carr M, Miller D, Feltell R, Thiru A, Bethell S, Devine LA, Graham BL, Pike A, Cosme J, Lewis EJ, Freyne E, Lyons J, Irving J, Murray C, Newell DR, Thompson NT (2011) Potent, selective inhibitors of fibroblast growth factor receptor define fibroblast growth factor dependence in preclinical cancer models. Mol Cancer Ther 10(9):1542-1552

28. Perera TPS, Jovcheval E, Vialard J, Verhulst T, Esser N, King P, Wroblowski B, Platero S, Querolle O, Mevellec L, Freyne E, Gilissen R, Murray C, Woodhead S, Fazal L, Saxty G, Newell D, Ward G, Squires M, Thompson N, Angibaud P (2014) JNJ-42756493 is an inhibitor of FGFR-1, 2, 3, and 4 with nanomolar affinity for targeted therapy. Poster \#1738 AACR annual meeting

29. Angibaud PR et al (2015) Identification of naphthyridines as potent inhibitors of fibroblast growth factor receptor kinase family. Poster \#3641 AACR annual meeting

30. Angibaud PR, Obringer M, Marin JJJ, Jeanty M. Preparation of naphthyridine derivatives useful in the treatment of cancer. WO 2013061077

31. Vermeulen W, Hostyn SA, Cuyckens FAC, Jones RM, Broggini DFD. Preparation of quinoxaline derivatives useful as FGFR kinase modulators. WO 2015144803

32. Nakanishi Y, Akiyama N, Tsukaguchi T, Tachibana-Kondo Y, Fujii T, Sakata K, Sase H, Isobe T, Sato Y, Morikami K, Shindoh H, Mio T, Ebiike H, Taka N, Aoki Y, Ishii N (2014) 
FGFR genetic alterations as a potential predictor of the sensitivity to CH5183284? Debio 1347, a novel selective FGFR inhibitor. Poster \#2729 AACR annual meeting

33. Ebiike H, Taka N, Nakanishi Y, Akiyama N, Sawamura F, Morikami K, Matsushita M, Ohmori M, Takami K, Hyohdoh I, Kohchi M, Hayase T, Nishii H, Ishii N, Matsuoka H (2014) Design and preclinical profile of CH5183284/Debio 1347, a novel orally available and selective FGFR inhibitor acting on a gatekeeper mutant of FGFR2. Poster \#2533 AACR annual meeting

34. Heroult M, Ellinghaus P, Sieg C, Brohm D, Gruenewald S, Collin M-P, Boemer U, Lobell M, Huebsch W, Ocker M, Ince S, Hagebarth A, Jautelat R, Hess-Stumpp H, Brands M, Ziegelbauer K (2014) BAY 1163877. Poster \#1739 AACR annual meeting

35. Heroult M, Ocker M, Kneip C, von Ashen O, Kopitz C, Zopf D, Hagebarth A, Ziegelbauer K, Ince S, Ellinghaus $P$ (2015) Anti-tumor efficacy of the selective pan-FGFR inhibitor BAY 1163877 in preclinical squamous-cell carcinoma models of different origin. Poster \#772 AACR annual meeting

36. Lobell M, Huebsch W, Schirok H, Heroult M, Brohm D, Collin M-P, Gruenewald S, Lustig K, Boemer U, Voehringer V, Lindner N. Preparation of substituted benzothienyl-pyrrolotriazines and uses thereof. WO 2013124316

37. Brohm D, Heroult M, Collin M-P, Huebsch W, Lobell M, Lustig K, Gruenewald S, Boemer U, Voehringer V. Preparation of disubstituted benzothienyl-pyrrolotriazines and their use as FGFR kinase inhibitors. WO 2013087578

38. Collin M-P, Brohm D, Heroult M, Lobell M, Huebsch W, Lustig K, Gruenewald S, Boemer U, Voehringer V, Lindner N Preparation of substituted benzothienylpyrrolotriazines as selective fibroblast growth factor receptor kinase inhibitors for treatment of cancer. WO 2013087647

39. Miyano SW, Yamamoto Y, Kodama K, Funaska S Nagao S, Sugi NH, Kuramochi H, Ishikawa K, Okamoto K, Minoshima Y, Nakagawa T, Nakatani Y, Karoji Y, Ohashi I, Yamane Y, Tanaka K, Okada T, Matsushima T, Matsui J, Iwata M, Tsuroka A, Uenaka T (2015) E7090: a potent and selective FGFR inhibitor with activity in multiple FGFR-driven cancer models with distinct mechanisms of activation. Poster \#770 AACR annual meeting

40. Lui PCC, Wu L, Koblish H, Bowman K, Zhang Y, Klabe R, Leffet L, DiMatteo D, Rupar M, Gallagher K, Hansbury M, Zhang C, He C, Collier P, Covington M, Wynn R, Yeleswaram S, Vaddi K, Burn T, Yao W, Huber R, Scherle P, Hollis G (2015) Preclinical characterization of the selective FGFR inhibitor INCB54828. Poster \#771 AACR Annual meeting

41. Sun L, Lu L, Yao W, Zhuo J, Wu L, Xu M, Qian D-Q, Zhang F, He C. Preparation of bicyclic heterocycles as FGFR inhibitors in the treatment of cancer. WO 2014172644

42. Wu L, Zhang C, He C, Sun Y, Lu L, Qian D-Q, Xu M, Zhuo J, Yao W. Preparation of substituted tricyclic compounds as FGFR inhibitors for treatment of cancer and other diseases. US 20130338134

43. Zhuo W, Hur W, McDermott U, Dutt A, Xian W, Ficarro SB, Zhang J, Sharma SV, Brugge J, Meyerson M, Settleman J, Gray NS (2010) A structure-guided approach to creating covalent FGFR inhibitors. Chem Biol 17:285-295

44. Packer ML, Pollock PM (2015) Paralog-specific kinase inhibition of FGFR4: adding to the arsenal of anti-FGFR agents. Cancer Discov 5(4):355-357

45. Wesche J, Haglund K, Haugsten EM (2011) Fibroblast growth factors and their receptors in cancer. Biochem J 437(2):199-213

46. Taylor VI JG, Cheuk AT, Tsang PS, Chung J-Y, Song YK, Desai K, Yu Y, Chen Q-R, Shah K, Youngblood V, Fang J, Kim SY, Yeung C, Helman LJ, Mendoza A, Ngo V, Staudt LM, Wei JS, Khanna C, Catchpoole D, Qualman SJ, Hewitt SM, Merlino G, Chanock SJ, Khan J (2009) Identification of FGFR4-activating mutations in human rhabdomyosarcomas that promote metastasis in xenotransplanted models. J Clin Investig 119(11):3395-3407

47. French DM, Lin BC, Wang M, Adams C, Shek T, Hotzel K, Bolon B, Ferrando R, Blackmore B, Schroeder K, Rodriguez LA, Hristopoulos M, Venook R, Ashkenazi A, Desnoyers LR (2012) Targeting FGFR4 inhibits hepatocellular carcinoma in preclinical mouse models. PLoS One 7(5):e36713 
48. Pike KG, Buttar D, Tucker J, Ford S, Glossop S, Culshaw J, Gill K, Perkins D, Eden J, Hayter B, Mooney L, Brooks N, Ruston L, Smith R, Jones C (2014) Identifying selective inhibitors of FGFR4 kinase. Oral presentation given at EFMC-ISMC 2014, XXIII international symposium on medicinal chemistry

49. Hagel M, Miduturu C, Sheets M, Rubin N, Weng W, Stransky N, Bifluco N, Kim JL, Hodous B, Brooijmans N, Shutes A, Winter C, Langauer C, Kohl NE, Guzi T (2015) First selective small molecule inhibitor of FGFR4 for the treatment of hepatocellular carcinomas with an activated FGFR4 signaling pathway. Cancer Discov 5(4):424-437

50. Winski S, Nanda N, Brown E, Tang T, Brandhuber B, Hamor R, Tuch B, Ebata K, Low J, Sullivan F, Smith D, Vigers G, Strough M, Rieger R, Blake J, Moreno D, Chantry D, Rothenberg SM, Andrews S (2015) Identification of first-in-class, highly potent FGFR kinase inhibitors that spare FGFR1. Abstract \#C196 AACR-NCI-EORTC international conference

51. Tucker JA, Klein T, Breed J, Breeze AL, Overman R, Philips C, Norman RA (2014) Structural insights into FGFR kinase isoform selectivity: diverse binding modes of AZD4547 and ponatinib in complex with FGFR1 and FGFR4. Structure 22:1764-1774

52. Eathiraj S, Palma R, Hirschi M, Volckova E, Nakuci E, Castro J, Chen C-R, Chan TCK, France DS, Ashwell MA (2011) A novel mode of protein kinase inhibition exploiting hydrophobic motifs of autoinhibited kinases. J Biol Chem 286(23):20677-20687 